\title{
Ex vivo dissection of optogenetically activated mPFC and hippocampal inputs to neurons in the basolateral amygdala: implications for fear and emotional memory
}

\author{
Cora Hübner ${ }^{1,2 \dagger}$, Daniel Bosch ${ }^{1 \dagger}$, Andrea Gall ${ }^{1}$, Andreas Lüthi $^{3}$ and Ingrid Ehrlich ${ }^{1 *}$ \\ ${ }^{1}$ Hertie Institute for Clinical Brain Research and Centre for Integrative Neuroscience, University of Tuebingen, Tuebingen, Germany \\ ${ }^{2}$ Graduate School of Neural and Behavioral Sciences, IMPRS, Tuebingen, Germany \\ ${ }^{3}$ Friedrich Miescher Institute for Biomedical Research, Basel, Switzerland
}

\author{
Edited by: \\ Anton Ilango, National Institutes of \\ Health, USA \\ Reviewed by: \\ Pankaj Sah, Queensland Brain \\ Institute, Australia \\ Francisco Sotres-Bayon, Universidad \\ Nacional Autónoma de México, \\ Mexico \\ ${ }^{*}$ Correspondence: \\ Ingrid Ehrlich, Hertie Institute for \\ Clinical Brain Research and Centre \\ for Integrative Neuroscience, \\ Otfried-Mueller-Str. 25, 72076 \\ Tuebingen, Germany \\ e-mail: ingrid.ehrlich@ \\ uni-tuebingen.de \\ tThese authors have contributed \\ equally to this work.
}

Many lines of evidence suggest that a reciprocally interconnected network comprising the amygdala, ventral hippocampus ( $\mathrm{vHC}$ ), and medial prefrontal cortex (mPFC) participates in different aspects of the acquisition and extinction of conditioned fear responses and fear behavior. This could at least in part be mediated by direct connections from mPFC or vHC to amygdala to control amygdala activity and output. However, currently the interactions between $\mathrm{mPFC}$ and $\mathrm{vHC}$ afferents and their specific targets in the amygdala are still poorly understood. Here, we use an ex-vivo optogenetic approach to dissect synaptic properties of inputs from mPFC and $\mathrm{VHC}$ to defined neuronal populations in the basal amygdala (BA), the area that we identify as a major target of these projections. We find that BA principal neurons (PNs) and local BA interneurons (INs) receive monosynaptic excitatory inputs from $\mathrm{mPFC}$ and $\mathrm{VHC}$. In addition, both these inputs also recruit GABAergic feedforward inhibition in a substantial fraction of PNs, in some neurons this also comprises a slow $\mathrm{GABA}_{B}$-component. Amongst the innervated PNs we identify neurons that project back to subregions of the mPFC, indicating a loop between neurons in MPFC and BA, and a pathway from $\mathrm{vHC}$ to $\mathrm{mPFC}$ via BA. Interestingly, mPFC inputs also recruit feedforward inhibition in a fraction of INs, suggesting that these inputs can activate dis-inhibitory circuits in the BA. A general feature of both MPFC and $\mathrm{VHC}$ inputs to local INs is that excitatory inputs display faster rise and decay kinetics than in PNs, which would enable temporally precise signaling. However, mPFC and vHC inputs to both PNs and INs differ in their presynaptic release properties, in that $\mathrm{VHC}$ inputs are more depressing. In summary, our data describe novel wiring, and features of synaptic connections from mPFC and vHC to amygdala that could help to interpret functions of these interconnected brain areas at the network level.

Keywords: medial prefrontal cortex, hippocampus, amygdala, conditioned fear, optogenetics

\section{INTRODUCTION}

Emotional information is processed in distinct neural circuits. Salient emotions such as fear and anxiety are among those most intensely investigated, because resulting behaviors can be easily evoked and studied in the laboratory and the underlying brain areas are highly conserved among mammalian species from mice to man (Ledoux, 2000; Phelps and Ledoux, 2005). The most powerful models used to date to elucidate the neural circuits and mechanisms that control fear are classical Pavlovian fear conditioning and extinction of acquired fear (Maren, 2001; Ehrlich et al., 2009; Herry et al., 2010; Pape and Pare, 2010). Fear conditioning involves pairing of a previous neutral stimulus (CS) with an aversive stimulus (US), such that a CS-US association is formed. During extinction training, the CS is repeatedly presented without the US, which leads to a decrease in the learned fear response. Many lines of evidence suggest that fear and extinction learning create two distinct memory traces, and which memory is retrieved depends on the retrieval context
(Bouton et al., 2006; Myers and Davis, 2007; Quirk and Mueller, 2008).

Although the amygdala is one of the most important brain areas for mediating fear and its extinction, the medial prefrontal cortex (mPFC) and hippocampus (HC), structures that are reciprocally connected to the amygdala, are implicated in aspects of acquisition, consolidation and retrieval of fear and extinction memories (Myers and Davis, 2007; Quirk and Mueller, 2008; Maren, 2011). Projections from mPFC to amygdala originate from layers 2 and 5 of different subregions, including the prelimbic (PL) and infralimbic (IL) areas and form asymmetric synapses (Pinto and Sesack, 2000, 2008). Tracing studies are not completely consistent regarding target nuclei in the amygdala. Projections from PL appear to target mainly the basal nucleus of the basolateral amygdala (BA) and portions of the capsular subdivision of the central amygdala $(\mathrm{CeC})$, whereas IL projections are generally less dense and target large parts of the amygdaloid complex including the intercalated cells, and more densely a specialized 
lateral part of the $\mathrm{CeC}$, and the ventromedial part of the $\mathrm{LA}$ as well as the magnocellular division of the BA (McDonald et al., 1996; Vertes, 2004; Pinard et al., 2012). Moreover, PL and IL receive amygdala projections originating mainly from the BA (Conde et al., 1995; Hoover and Vertes, 2007). Recently it has been shown that BA neurons projecting to IL and PL have opposing roles in expression of fear following extinction learning (Senn et al., 2014). Together, this raises the possibility that IL and PL may interact with the amygdala by virtue of their reciprocal connections to influence the outcome of fear and extinction learning. Projections from HC to amygdala originate in the temporal subiculum and the adjacent part of CA1. Subicular projections are dense in the accessory basal $(\mathrm{AB})$ and medial part of $\mathrm{BA}$, but moderate in LA and light in central amygdala, while CA1 projections to the amygdala mainly terminate in the $\mathrm{BA}$, with lighter projections to LA and AB (Canteras and Swanson, 1992; Pitkanen et al., 2000). The ventral HC (vHC) is thought to contribute contextual information following extinction learning either via direct amygdala projections or indirectly by strong projections to the mPFC, which subsequently projects to the amygdala (Hoover and Vertes, 2007; Pape and Pare, 2010; Orsini et al., 2011).

Systems-level studies started to elucidate specific functions of mPFC and hippocampal regions and their interactions with the amygdala in fear learning, fear expression and extinction of fear (Maren and Quirk, 2004; Pape and Pare, 2010; Maren, 2011). For example, synchronization of activity in amygdala-hippocampalprefrontal cortical circuits plays a critical role in anxiety, acquired fear, extinction learning, and fear discrimination (Seidenbecher et al., 2003; Lesting et al., 2011; Likhtik et al., 2014), but the underlying connectivities of neurons and microcircuits are still incompletely understood. The mPFC appears to play a double role in high and low fear states. Activation of the IL suppresses fear by suppressing amygdala output possibly via intercalated cells and central amygdala inhibition (Quirk et al., 2003; Paré et al., 2004; Maren, 2011), and/or via local BLA interneurons (Rosenkranz and Grace, 2001, 2002). The PL is thought to excite the amygdala to increase fear output during fear expression and renewal (Vidal-Gonzalez et al., 2006; Orsini et al., 2011; Sierra-Mercado et al., 2011). However, in vivo recordings of neuronal responses in the BLA during mPFC stimulation have yielded conflicting results about amygdala activation (Rosenkranz and Grace, 2001, 2002; Likhtik et al., 2005). Also, few data are available on how hippocampal activity influences BLA activity (Maren and Fanselow, 1995; Hobin et al., 2003; Maren and Hobin, 2007). It has been proposed that both hippocampal and PL projections to the BA mediate context-dependent fear renewal (Orsini et al., 2011), but if and how these inputs converge in the BA has not been studied.

Thus, a key open question that will guide our understanding and interpretation of systems-level functions and mechanisms, is to decipher the functional connectivities in amygdalahippocampal-prefrontal circuits including innervation of distinct cell types, delineation of similarities or differences in synaptic input properties, and the recruitment of specific microcircuits. Here, we use an ex vivo optogenetic approach to study the properties of mPFC and vHC inputs to specific subtypes of BA neurons and describe distinct wiring principles and synaptic properties between these three structures.

\section{MATERIALS AND METHODS ANIMALS}

For all experiments, we used adult male mice (8-12 week old at time of slice recordings) of the following lines: C57BL/6J (Harlan, Netherlands), glutamate decarboxylase 67 (GAD67)-green fluorescent protein (GFP) transgenic mice (Tamamaki et al., 2003) backcrossed to C57BL/6J, and Parvalbumin-Cre (PV-Cre, Jackson stock 008069) mice crossed to Ai14 reporter mice (Jackson stock 007914) that were backcrossed to C57BL/6J. All experimental procedures were in accordance with the $\mathrm{EU}$ directive on use of animals in research and approved by the Regierungspraesidium Tuebingen, state of Baden-Wuerttemberg, Germany.

\section{STEREOTACTIC INJECTIONS}

Four to six week old mice were maintained under isoflurane anesthesia, fixed in a stereotactic frame (Stoelting, USA) and injected bilaterally in either the mPFC or ventral hippocampus or a combination of both at the following coordinates from bregma (in mm). mPFC: posterior 1.9, lateral \pm 0.3 , ventral -2.1 ; ventral hippocampus: posterior -3.1 , lateral \pm 3.4 , ventral -3.8. Pressure injections were performed using glass capillaries (1B150F-4, WPI, Germany) attached to a Toohey Spritzer (Toohey Company, USA). For mPFC inputs, the mPFC was injected either with $0.5 \mu l$ of rAAV-CAG-hChR2(H134R)mCherry (serotype $2 / 1$ or 2/9, Penn Vector Core, USA) alone or with a $0.5 \mu \mathrm{lmix}$ of rAAV-hSyn.hChR2(H134R)-eYFP (serotype 2/9, Penn Vector Core, USA) and red retrobeads (Lumafluor, USA). For hippocampal inputs, the ventral hippocampus was injected with $0.5 \mu \mathrm{l} \mathrm{rAAV-hSyn.hChR2(H134R)-eYFP}$ and the mPFC was injected with $0.4 \mu \mathrm{l}$ red retrobeads. In all cases, viral preps were diluted such that they had comparable titers $(1 \times$ $10^{12} \mathrm{GC} / \mathrm{ml}$ ). Retrobeads were dialyzed against $0.32 \mathrm{M}$ sucrose prior to use to avoid osmotic damage of the tissue. Four to six weeks postinjection, amygdala slices were prepared for slice recordings.

\section{SLICE RECORDINGS}

Coronal or horizontal (tilted $35^{\circ}$ from horizontal plane) (Morozov et al., 2011) acute brain slices were prepared in icecold artificial cerebrospinal fluid (ACSF) supplemented with $8.7 \mathrm{mM} \mathrm{MgSO}_{4}$ at $320 \mu \mathrm{m}$ thickness using a vibrating microtome (HM650V, Microm, Germany) equipped with a sapphire blade (Delaware Diamond Knives, USA). Slices were recovered at $37^{\circ} \mathrm{C}$ for $45 \mathrm{~min}$ and stored at room temperature in ACSF composed of (in mM): $124 \mathrm{NaCl}, 1.25 \mathrm{NaH}_{2} \mathrm{PO}_{4}, 1.3 \mathrm{MgSO}_{4}, 2.7 \mathrm{KCl}$, $26 \mathrm{NaHCO} 3,2 \mathrm{CaCl} 2,18 \mathrm{D}$-glucose, $4 \mathrm{~L}$-ascorbic acid and oxygenated with 95\% O2, 5\% CO2 until recording. Slices containing the amygdala were transferred to a submersion recording chamber, superfused with oxygenated ACSF at a speed of $1-2 \mathrm{ml} / \mathrm{min}$, and maintained at $30-31^{\circ} \mathrm{C}$. Oblique infrared and fluorescence illumination were used to target unlabeled or retrobead-labeled principal neurons, and GFP- or dtTomato-expressing interneurons for recording. Whole-cell patch-clamp recordings were performed using pipettes pulled from borosilicate glass capillaries (GB150F-8P, Science Products, Germany) with resistances of 5-8 M $\Omega$. For most whole cell recordings, the intracellular solution contained (in $\mathrm{mM}$ ): $130 \mathrm{~K}$-Gluconate, $5 \mathrm{KCl}, 4 \mathrm{Mg}$-ATP, 
0.4 Na-GTP, $10 \mathrm{Na}_{2}$-phosphocreatine, 10 HEPES, 0.6 EGTA and had an osmolarity of 290-295 mOsm and $\mathrm{pH}$ of 7.2-7.3. In some recordings $0.5 \% \mathrm{w} / \mathrm{v}$ biocytin was included in the intracellular solution. Some recordings were performed in Cs-based internal solution containing (in mM): $135 \mathrm{Cs}$-Methylsulphonate, $6 \mathrm{CsCl}$, $4 \mathrm{Mg}$-ATP, 0.4 Na-GTP, $10 \mathrm{Na}_{2}$-phosphocreatine, $10 \mathrm{HEPES}, 0.6$ EGTA and had an osmolarity of 290-295 mOsm and $\mathrm{pH}$ of 7.2-7.3. Data were acquired using a Multiclamp $700 \mathrm{~B}$ amplifier, Digidata 1440 AD-board, and Clampex software (all from MDS, USA). Signals were filtered at $2 \mathrm{kHz}$ and digitized at $5 \mathrm{kHz}$ for synaptic current recordings and filtered at $10 \mathrm{kHz}$ and digitized at $20 \mathrm{kHz}$ for current-clamp recordings. Series resistance was monitored throughout each experiment and data were excluded if it changed $>20 \%$. ChR2-expressing fibers were activated with brief light pulses $\left(0.6-2 \mathrm{~ms}, 5-10 \mathrm{~mW} / \mathrm{mm}^{2}\right)$ from a light emitting diode (470 nm, KSL70, Rapp Opto-Electronics, Germany) delivered to the whole field through the $40 \times 0.8$ NA objective of the upright microscope (BX51WI, Olympus, Japan). All chemicals were reagent grade (from Roth, Merck, or Sigma, Germany). CNQX was obtained from Biotrend (Germany), Picrotoxin was obtained from Sigma (Germany).

\section{IMMUNOSTAINING AND IMAGING}

After recording, amygdala slices were fixed in 4\% PFA in phosphate buffered saline (PBS) for $16-24 \mathrm{~h}$ at $4^{\circ} \mathrm{C}$. Slices were embedded in a block of 2\% Agar-Agar and resectioned at $70 \mu \mathrm{m}$. For visualization of projections within the amygdala, some sections were stained with Neurotrace (1:200, Invitrogen). Other sections that contained filled cells were permebealized in $0.3 \%$ Triton-X100 in PBS, and biocytin-filled cells were revealed using fluorescently-conjugated Steptavidin-Cy5 (1:200, Dianova, Germany). Immunostainings for parvalbumin were performed using standard procedures using mouse antiParvalbumin (Sigma, 1:2000) and Alexa-405-conjugated goatanti-mouse (Invitrogen, 1:1000) antibody. Sections were imaged using a laser scanning confocal microscope (LSM 710, Carl Zeiss, Germany) equipped with a $25 \times 0.8^{\circ} \mathrm{NA}$ for overview of projections or filled cells, or a $63 \times 1.4^{\circ} \mathrm{NA}$ objective and the pinhole set to 1 airy unit for colocalization of markers in filled cells.

\section{LOCALIZATION OF INJECTION SITES AND FIBERS}

Coronal hippocampal sections were cut right after amygdala sections, immediately imaged on a fluorescent stereoscope (SCX16, Olympus, Japan) to confirm viral injection sites, and slices were fixed in 4\% PFA in PBS for further analyses. The frontal cortex was removed, fixed overnight in $4 \%$ PFA in PBS, resectioned at $70 \mu \mathrm{m}$, and stained with Neurotrace (1:200, Invitrogen). Bead only injection sites in the $\mathrm{mPFC}$ were imaged using a fluorescent stereoscope. Viral and bead injection sites in the mPFC were imaged on a laser scanning confocal microscope either with a $10 \times 0.3^{\circ} \mathrm{NA}$ or a $25 \times 0.8^{\circ} \mathrm{NA}$ objective with the pinhole open or set to one airy unit as indicated. All images were overlaid with the mouse brain atlas (Paxinos and Franklin, 2001).

\section{DATA ANALYSIS AND STATISTICS}

All electrophysiological data were analyzed using the NeuroMatic suite of macros (http://www.neuromatic.thinkrandom.com/) and additional custom-written macros in IgorPro (Wavemetrics, USA). Input resistance (Rinput), series resistance (Rseries), membrane time constant and capacitance were calculated from $100 \mathrm{~ms}$ long, $-5 \mathrm{mV}$ voltage steps applied from a holding potential (Vhold) of $-70 \mathrm{mV}$ and were monitored throughout the experiment. Resting membrane potential was measured right after breaking into the cell by switching to current-clamp mode. Spiking patterns were elicited by applying depolarizing currents from 0 to $+200^{\circ} \mathrm{pA}$ in $50^{\circ} \mathrm{pA}$ steps. Spike parameters were determined from the smallest current step that evoked one or a few action potentials. Spike threshold was determined as the voltage at which a $>8$-fold change in the rate of rise (in $\mathrm{mV} / \mathrm{ms}$ ) occurred. Spike amplitude was measured as the voltage difference between spike threshold and the peak of the spike. The spike half-width was measured as time difference between up- and downstroke of the spike at half-maximal amplitude. The fast afterhyperpolarization (fAHP) was measured in a $15 \mathrm{~ms}$ window after the peak of the spike, as the most negative membrane potential relative to the spike threshold. Synaptic current parameters were measured using Neuromatic functions on an average response generated from at least 10 individual sweeps. Amplitudes were measured as a negative or positive peak, or for late inhibitory currents as the average in a $1 \mathrm{~ms}$ time window $300 \mathrm{~ms}$ after stimulation. EPSC rise time was the time between $10-90 \%$ of maximal amplitude, and EPSC decay time was determined as time it took for the EPSC peak to decay to $37 \%$ of maximal amplitude. Latencies were measured as time between onset of stimulation and onset of the synaptic response.

Since recordings for specific group comparisons were all conducted with the same solutions and under identical conditions, we did not correct our data for the liquid junction potential. All data are reported as mean \pm standard error of the mean. Statistical comparisons were performed using SPSS software (IBM, USA). For nominal data, Fisher's Exact Test or $\chi^{2}$-Test were used as indicated. Scaled data comparisons were performed using unpaired or paired Students $t$-test as indicated.

\section{RESULTS}

To dissect which neurons in the amygdala receive inputs from $\mathrm{mPFC}$ and $\mathrm{vHC}$, to characterize properties of these inputs, and to assess activated microcircuits, we used an ex-vivo optogenetic approach. We injected mice with recombinant Adeno-associated virus (rAAV) expressing the light activatable protein channelrhodopsin fused to either mCherry or eYFP. Viral injections into the mPFC either infected neurons mainly located in PL or IL, or a larger area of the $\mathrm{mPFC}$, encompassing PL and IL, and sometimes parts of adjacent regions (Figures 1A,E-G). For all mPFC injection conditions, dense fluorescently labeled fibers were observed in the medial BA (Figure 1B). Injections into the hippocampus were targeted toward the caudal and ventral part $(\mathrm{vHC}$, Figures 2A,B) resulting in labeled fibers in the medial BA and BMA (Figures $\mathbf{2 G}, \mathbf{H}$ ). In some of the animals with viral injections to $\mathrm{mPFC}$ or $\mathrm{vHC}$, we also injected a retrograde tracer (retrobeads) to label mPFC-projecting principal neurons in the BA for recording (Figures 1C,D, 2C,H). To identify interneurons in live brain slices, we used GAD-67-GFP reporter mice (Tamamaki et al., 

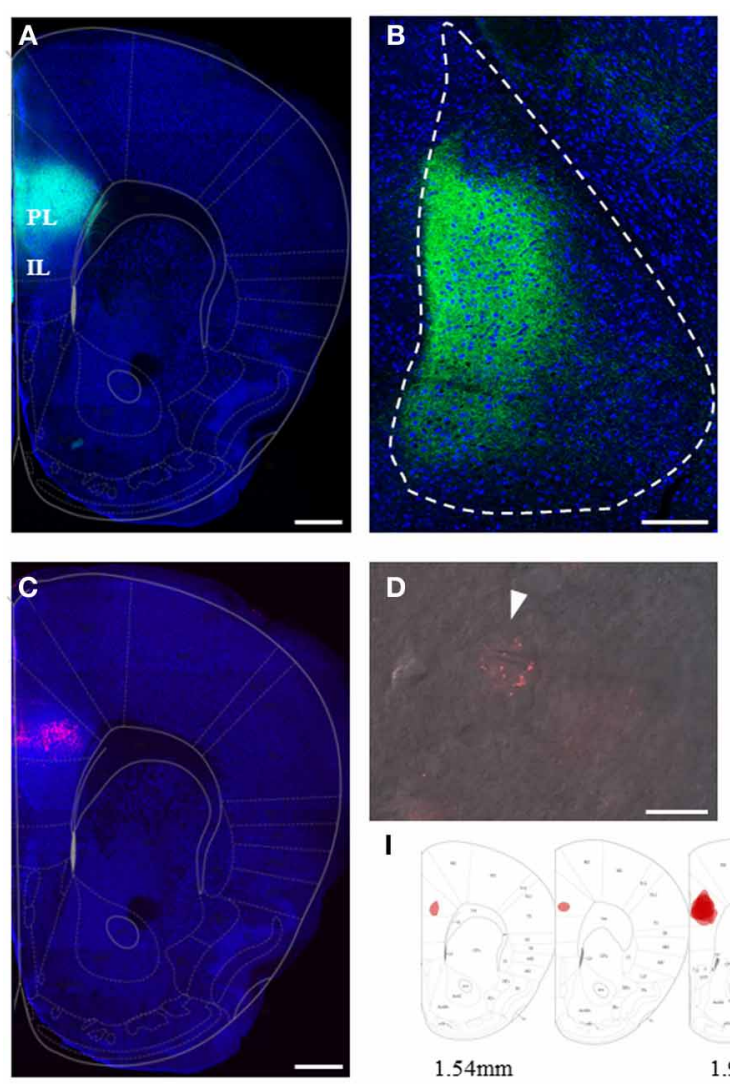

I

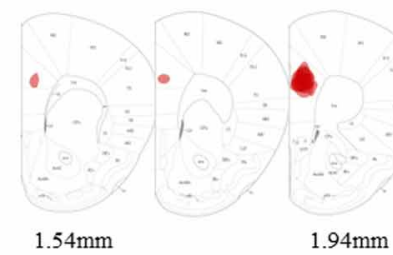

E

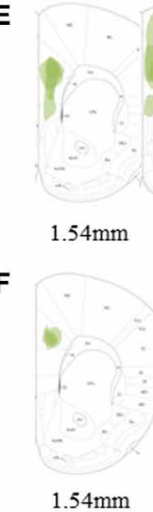

G

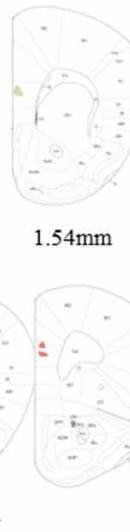

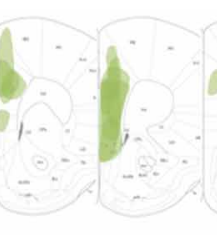

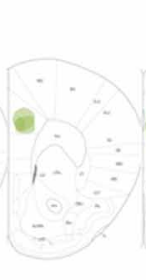

$1.98 \mathrm{~mm}$

$2.34 \mathrm{~mm}$

$-2$

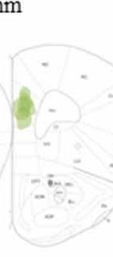

$1.94 \mathrm{~mm}$

H
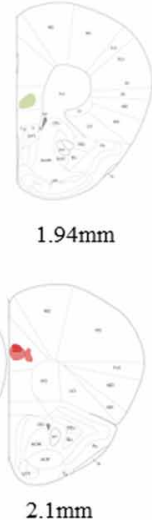
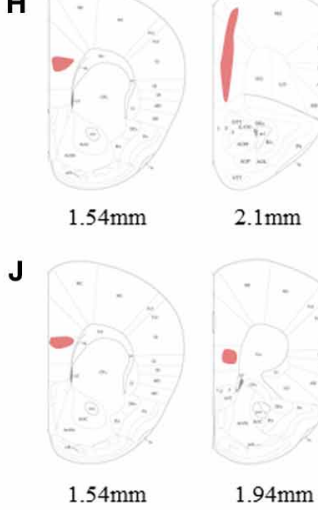

FIGURE 1 | Viral and bead injection sites for studying MPFC inputs to BLA. (A) Confocal image of a representative brain slice of an animal injected in the mPFC with rAAV-ChR2(H134R)-eYFP (green). Scale bar: $500 \mu \mathrm{m}$. (B) Confocal image of a $35^{\circ}$ tilted horizontal brain slice of the BLA with mPFC projections (green) corresponding to the injection site of (A). Scale bar: $250 \mu \mathrm{m}$. (C) Confocal image of a representative brain slice with retrobead injection site restricted to the $\mathrm{PL}$ region of the $\mathrm{MPFC}$ (red). Scale bar: $250 \mu \mathrm{m}$. (D) Image of an ex vivo recorded retrogradely labeled PN in the BA. Scale bar: $10 \mu \mathrm{m}$. (E-G) Overlay of mPFC viral injection sites (green) with the mouse brain atlas for animals categorized as having main injection sites in (E) $\operatorname{mPFC}(n=13),(\mathbf{F}) \operatorname{PL}(n=17)$ and (G) IL $(n=2)$. (H-J) Overlay with the mouse brain atlas for animals categorized as having the main retrobead injection site in $\mathbf{( H )}$ mPFC $(n=2)$, (I) $\mathrm{PL}(n=13)$ and (J) $\mathrm{IL}(n=2)$.
2003), and in a few experiments PV-Cre mice crossed with a red reporter mouse (Madisen et al., 2010).

\section{PREFRONTAL AND HIPPOCAMPAL INPUTS DIFFERENTIALLY RECRUIT EXCITATORY AND INHIBITORY RESPONSES IN BA PRINCIPAL NEURONS AND INTERNEURONS}

We focused our recordings on neurons located in the medial part of the $\mathrm{BA}$, the region where both, labeled $\mathrm{mPFC}$ and $\mathrm{vHC}$ axons were reliably observed in acute brain slices. Importantly, passive and active properties of principal neurons that received inputs from $\mathrm{mPFC}$ or the vHC were nearly indistinguishable (Table 1), and consistent with those recently described for recordings from the magnocellular region of the BA in mice (Senn et al., 2014). To study responses elicited by activation of channelrhodopsinpositive axons from the mPFC or vHC, we first recorded from principal neurons (PNs) and interneurons (INs) in currentclamp mode. As expected from a glutamatergic projection, all light-responsive PNs and INs displayed an initial depolarizing response that resembled an excitatory postsynaptic potential (EPSP, Figures 3A,B). With increasing stimulation intensity, a fraction of both PNs and INs responded with a spike arising from the EPSP (Figure 3A, bottom). In PNs, spikes were more readily elicited by $\mathrm{mPFC}$ - than $\mathrm{vHC}$-fiber stimulation, while INs were equally likely to show spike responses for the two input pathways (Figure 3B). Under conditions where we did not elicit spikes in PNs, we observed also two types of hyperpolarizing responses, resembling fast and slow inhibitory postsynaptic potentials, which we called early and late IPSPs (Figure 3C). Stimulation of mPFC inputs elicited IPSPs in a substantial and similar fraction of PNs and INs (46-66\%). In contrast, vHC afferent stimulation recruited IPSPs in a significantly larger fraction of PNs than INs (60 vs. 13\%, Figure 3D). When comparing inputs, IPSPs were equally prevalent in PNs following stimulation of either mPFC or vHC inputs, whereas in INs, mPFC inputs were more likely to evoke IPSPs than vHC inputs (Figure 3D). This suggests that activation of the vHC recruits less inhibition onto INs when compared to PNs, or to neurons innervated by the mPFC.

In a second step, we addressed if activation of IL- vs. PLafferents would show different response profiles, by analyzing 


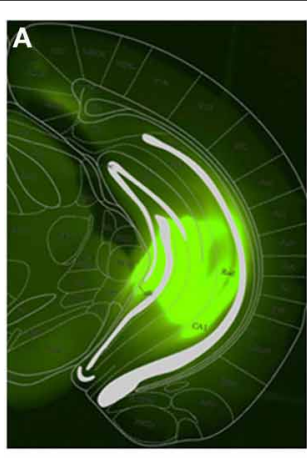

\section{B}

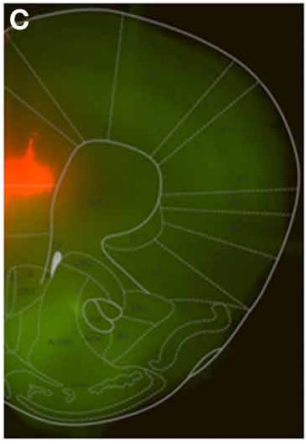

D
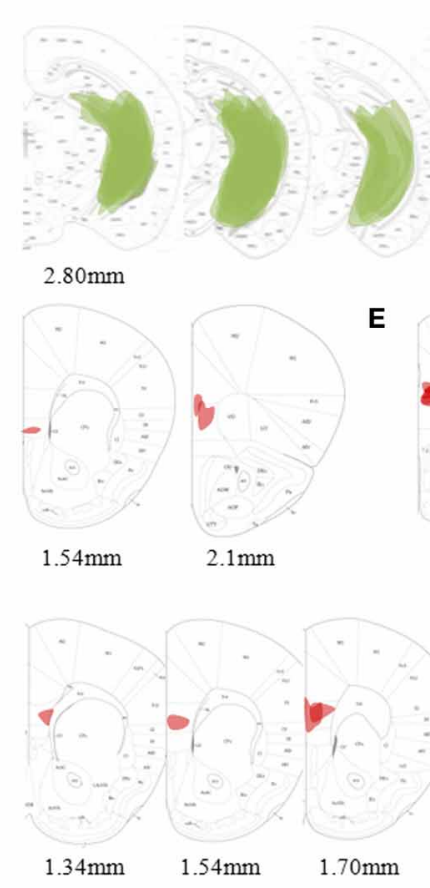

E

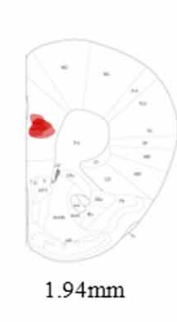

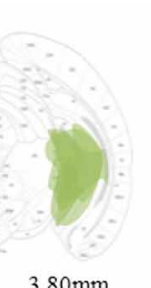

$3.80 \mathrm{~mm}$
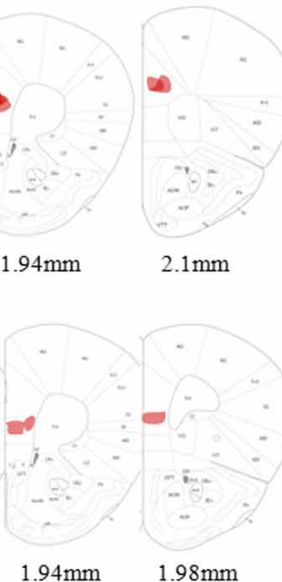
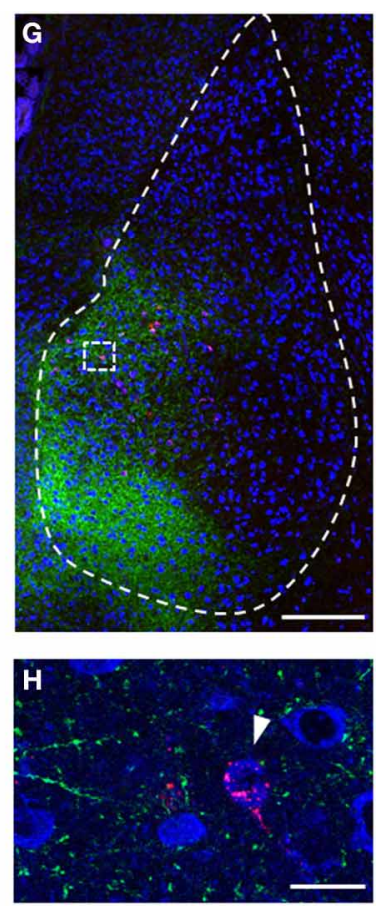

FIGURE 2 | Viral and bead injection sites for studying hippocampal inputs to BLA. (A) Stereoscopic picture of a representative brain slice of an animal injected in the ventral hippocampus $(\mathrm{vHC})$ with rAAV-ChR2(H134R)-eYFP (green). (B) Overlay of vHC viral injection sites with the mouse brain atlas for all animals analyzed $(n=23)$. (C) Stereoscopic picture of a representative brain slice with retrobead injection site in the mPFC (red) of the same animal. (D-F) Overlay of main retrobead injection sites with the mouse brain atlas for all animals categorized as having the main injection site in (D) mPFC $(n=2)$, (E) PL $(n=5)$ and (F) IL $(n=8)$. (G) Confocal image of a coronal brain slice of the BLA with $\mathrm{VHC}$ projections (green) and retrogradely labeled principle neurons projecting to the MPFC (red) of the animal shown in (A) and (C). Scale bar: $250 \mu \mathrm{m}$. (H) Close-up of insert from (G) with $\mathrm{VHC}$ projections and retrobead-labeled neurons in the medial BA. Scale bar: $20 \mu \mathrm{m}$. subsets of neurons activated by fibers from localized IL and PL injections. Interestingly, we found no significant difference in excitatory or inhibitory response types onto PNs, or in the prevalence of excitatory and inhibitory input types from the PL to PNs vs. INs (Figures 3E,F). Although the dataset for IL inputs onto INs is very limited, overall our data suggest that IL and PL fiber activation leads to similar response type profiles for excitation and inhibition onto medial BA PNs and INs in naïve animals.

\section{SYNAPTIC RESPONSES ARE COMPRISED OF EARLY EPSCS AND

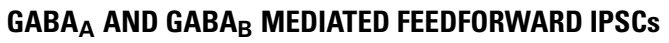

To confirm that light responses were generated by axonal activation and to dissect synaptic components, we performed voltage-clamp recordings. In keeping with our initial observation, we found that all PNs and INs showed light-evoked inward currents at $-70 \mathrm{mV}$, which resembled excitatory postsynaptic currents (EPSCs, Figures 4A-F). These putative EPSCs were completely abolished by application of the sodium channel blocker tetrodotoxin (TTX, $1 \mu \mathrm{M}$ ), indicating that they were driven by action potentials in ChR2-expressing axons $(n=3$, data not shown). Neurons with only EPSP-like responses in current-clamp mode displayed a single component current response with a reversal potential close to $0 \mathrm{mV}$ following $\mathrm{mPFC}$ or $\mathrm{vHC}$ fiber stimulation (Figures 4A,D,G). These responses were completely blocked by the AMPA/Kainate receptor antagonist CNQX
(10 $\mu \mathrm{M}, n=3$, Figure $4 \mathrm{H}$ left), indicating that they represent glutamatergic EPSCs. Recordings from neurons with a depolarizing and early hyperpolarizing profile revealed two current components in voltage-clamp recordings: an early component with a reversal potential close to $0 \mathrm{mV}$ and a second component with a reversal potential close to $-70 \mathrm{mV}$, the expected equilibrium potential for chloride, and thus $\mathrm{GABA}_{\mathrm{A}}$-mediated inhibitory postsynaptic currents (IPSCs, Figures 4B,E,G). Consistent with the notion of an EPSC/earlyIPSC sequence, the second component was blocked by picrotoxin (PTX, $100 \mu \mathrm{M}, n=9$ ), and the first component was blocked by subsequent application of CNQX ( $n=6$, Figure 4I, left). Furthermore, the biphasic EPSC/earlyIPSC was also completely abolished by CNQX alone ( $n=2$, Figure $4 \mathbf{H}$, right), a finding that is in agreement with feedforward inhibition. Lastly, we examined neurons with a late hyperpolarization in current-clamp mode. Here, we always found three current components, the first reversing around $0 \mathrm{mV}$ (consistent with an EPSC), a second reversing around $-70 \mathrm{mV}$ (consistent with the early IPSC described above) and a third, small component with a reversal potential close to $-90 \mathrm{mV}$, the expected equilibrium potential for potassium und thus, the effector channels of $\mathrm{GABA}_{\mathrm{B}}$ receptors (Figures $4 \mathrm{C}, \mathbf{F}, \mathbf{G}$ ). Here, the $\mathrm{GABA}_{\mathrm{A}}$ antagonist PTX only blocked the early IPSC, and subsequent application of CNQX abolished the EPSC and late IPSC ( $n=1$, Figure 4I, right). Thus, neurons with a late 


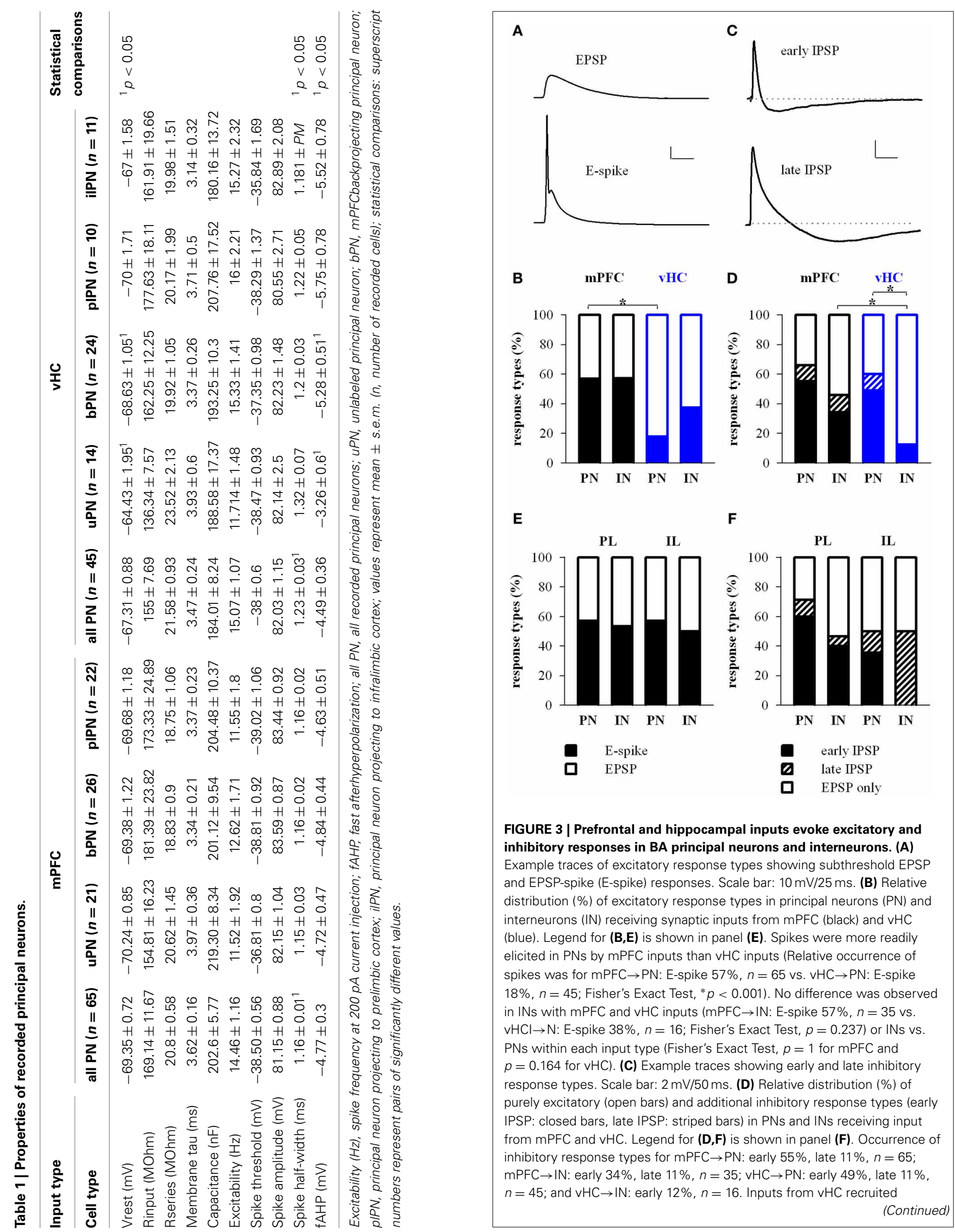




\section{FIGURE 3 | Continued}

IPSPs more readily in PNs compared to INs ( $n=27 / 45$ vs. $n=2 / 16$; Fisher's Exact Test, $* p=0.001)$. In INs, mPFC inputs recruited IPSPs more readily than $\mathrm{vHC}$ inputs ( $n=16 / 35$ vs. $n=2 / 16$; Fisher's Exact Test, ${ }^{*} p=0.028$ ). (E) Relative distribution (\%) of excitatory response types in neurons receiving synaptic input from prelimbic (PL) and infralimbic (IL) regions of the $\mathrm{mPFC}$. Relative occurrence of spikes was for $\mathrm{PL} \rightarrow \mathrm{PN}$ : $57 \%$, $n=35 ; \mathrm{IL} \rightarrow \mathrm{PN}: 57 \%, n=14$ neurons; $\mathrm{PL} \rightarrow \mathrm{IN}: 53 \%, n=15 ; \mathrm{IL} \rightarrow \mathrm{IN}: 50 \%$, $n=2$. No difference in excitatory response types was observed (Fisher's Exact Test, all $p=1$ ) (F) Relative distribution (\%) of purely excitatory (open bars) and early and late inhibitory (closed and striped bars, respectively) response types in neurons receiving synaptic input from $P L$ and IL regions of the mPFC. Occurrence of inhibitory response types for $\mathrm{PL} \rightarrow \mathrm{PN}$ : early $60 \%$, late $11 \%, n=35$; and $\mathrm{PL} \rightarrow \mathrm{IN}$ : early $40 \%$, late $7 \%, n=15 ; \mathrm{IL} \rightarrow \mathrm{PN}$ : early $36 \%$, late $14 \% ; n=14 ; \mathrm{IL} \rightarrow \mathrm{IN}$ : early $0 \%$, late $50 \%, n=2$. There was no difference in inhibitory response types (Fisher's Exact Test, all $p>0.25$ ).

inhibition also display an early inhibitory response in voltageclamp mode. We also isolated EPSCs and early IPSCs in Cs-based internal solution to precisely determine their onset latencies. Latencies of EPSC were consistently shorter than latencies of early IPSC latencies in a within-cell comparison (Figures 5A,B). Furthermore, the values are well in line with recent studies on optogenetic monosynaptic and disynaptic activation of EPSCs and IPSCs, respectively (Cho et al., 2013; Felix-Ortiz et al., 2013). Late IPSCs were not observed in Cs-based recordings, lending further support to their potassium-channel/GABA $\mathrm{G}_{\mathrm{B}}$ receptor based mechanism.

In conclusion, our data show that neurons in the BA receive either exclusively excitatory glutamatergic inputs or a combination of excitatory and inhibitory inputs from mPFC and vHC. Although we cannot completely exclude a contribution of feedback inhibition, our findings strongly suggest that at least early inhibition is due to feedforward processes. Feedforward inhibition was frequently observed in BA PNs for both inputs $(>60 \%)$, and prominent at mPFC inputs to INs, but rarely observed for vHC inputs onto INs (Figure 5C). Postsynaptic inhibition can either be mediated by $\mathrm{GABA}_{\mathrm{A}}$ receptors, or a combination of $\mathrm{GABA}_{\mathrm{A}}$ and $\mathrm{GABA}_{\mathrm{B}}$ receptors.

\section{PROPERTIES OF MPFC- AND vHC-EVOKED EXCITATORY INPUTS IN BA DEPEND ON INPUT AND TARGET CELL TYPE}

To address if excitatory inputs onto different types of BA neurons have distinct properties, we compared EPSCs between PNs and INs in each input pathway and between input pathways. In all cases, synaptic latencies of EPSCs were consistent with monosynaptic activation (Tables 2, 5). When comparing EPSC kinetics between neuron types, INs showed more rapid rise and decay times than PNs in both input pathways (Figures 6A,B), a feature previously described for local interneurons in hippocampus and amygdala (Mahanty and Sah, 1998; Jonas et al., 2004). Consistent with that, EPSCs in INs had similarly fast kinetics when comparing $\mathrm{mPFC}$ and $\mathrm{vHC}$ inputs (Table 5, Figures 6A,B). Interestingly, when comparing PNs, we found that EPSCs evoked by vHC input had a decreased latency and slightly but significantly faster rise and decay times than those originating from $\mathrm{mPFC}$ inputs (Table 2, Figures 6A,B).
To assess presynaptic properties, we performed paired-pulse stimulation and analysis. Because our TTX experiments suggested action potential-dependent neurotransmitter release, and ChR2(H134R) can follow stimulation frequencies up to $40 \mathrm{~Hz}$ reliably (Berndt et al., 2011), we used intervals between 50 and $300 \mathrm{~ms}$ for stimulation. At all intervals tested, we found a significant difference in the paired-pulse ratio (PPR) between mPFC and vHC inputs onto PNs and INs with consistently lower values for $\mathrm{vHC}$ inputs (Figures 6C,D). At the $50 \mathrm{~ms}$ interval, the PPR of vHC inputs was strongly depressing, suggesting a high release probability of these synapses, whereas mPFC inputs to PNs and INs showed higher values (around 1), suggesting a lower release probability (Figures 6C,D).

In our dataset, mPFC inputs to PNs evoked larger EPSCs than vHC inputs (Table 2). To rule out that the observed differences in PPR and EPSC kinetics between inputs may be due to amplitude differences, we used two approaches. Firstly, we performed amplitude-restricted analysis of EPSC properties (criterion: amplitudes $<500 \mathrm{pA} ; \mathrm{mPFC} \rightarrow \mathrm{PN}:-2.1 \pm 22 \mathrm{pA}, n=40$; $\mathrm{vHC} \rightarrow \mathrm{PN}:-2.0 \pm 23 \mathrm{pA}, n=37 ; p=0.081)$ and still detected significant differences in latency, rise, decay and PPR $(p \leq 0.01$ for all). Secondly, we performed correlation analysis on both datasets. We found no correlation between amplitude vs. latency, kinetics, or PPR for vHC inputs ( $p \geq 0.05$ for all), and an opposite than expected correlation between amplitude and latency and amplitude and rise time for mPFC inputs (i.e., larger EPSC had faster latencies and shorter rise times, $p<0.05$ ). Thus, in conclusion, differences in $\mathrm{mPFC}$ vs. $\mathrm{vHC}$ input properties did not result from amplitude differences. If faster latencies and kinetics of EPSCs in vHC inputs would result from dendritic filtering and/or synapse location, these parameters should be positively correlated. Indeed, we found a highly significant correlation between latency and rise time $\left(n=42, R^{2}=0.43 ; p<0.0001\right)$ and rise and decay time ( $\left.n=42, R^{2}=0.21 ; p=0.002\right)$.

In summary, EPSCs in INs displayed faster rise and decay times and lower PPRs when compared to their PN counterparts, features that would allow them to rapidly and reliably function in feedforward inhibitory circuits. Furthermore, vHC inputs are generally faster and more depressing than MPFC inputs. This is unlikely due to differences in the passive and active properties of target principal neurons (Table 1), or variability of EPSC amplitudes, but likely a feature resulting from differences in pre- and postsynaptic properties and location of specific inputs.

\section{OVERALL INHIBITION/EXCITATION RATIO IS SIMILAR FOR DIFFERENT INPUT TYPES}

Although feedforward inhibition was observed with equal likelihood for $\mathrm{mPFC}$ and $\mathrm{vHC}$ inputs onto PNs, and also for mPFC inputs onto INs, one possibility is that the amount of inhibition could be different. We estimated the inhibitory drive by calculating the inhibition/excitation ratio (I/E ratio) from the peak amplitudes of the inward and outward components of the biphasic EPSC/IPSC recorded at $-50 \mathrm{mV}$ (Shin et al., 2006) (Figure 7A). The I/E ratio was highly variable, but on average not significantly different for $\mathrm{mPFC}$ vs. vHC inputs onto PNs (Figure 7B). There was also no difference in the I/E ratio between mPFC inputs onto PNs vs. INs (Figures 7A,B). Furthermore, activation of fibers 


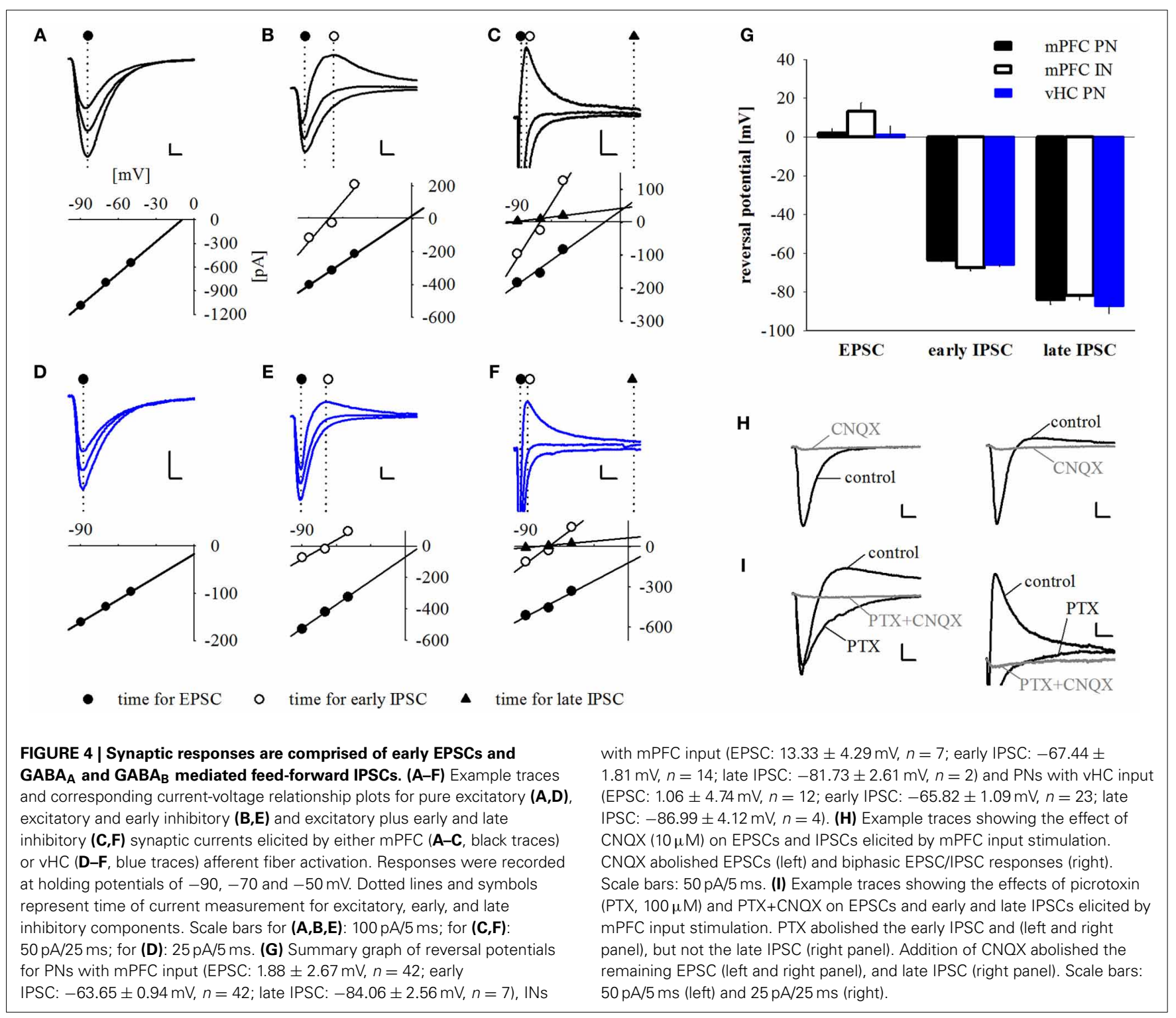

from subregions of the mPFC (large mPFC injections vs. specific PL and IL injections) did not show any significant differences in $\mathrm{I} / \mathrm{E}$ ratios (Figure 7C). Taken together, in naive animals, our data indicate no clear differences in the strength of recruited feedforward inhibition when normalized to excitation between PNs and INs, and between different input types.

\section{DISSECTION OF PROJECTION NEURON POPULATIONS TARGETED BY mPFC AND vHC AFFERENTS}

Projection neurons within the BA have diverse targets within and outside of the amygdala. In fear and extinction learning, changes in the activity of mPFC-projecting BA neurons play a critical role (Herry et al., 2008; Senn et al., 2014), while other types of projection neurons regulate anxiety-like behavior (Tye et al., 2011; Felix-Ortiz et al., 2013). Thus, we investigated properties of $\mathrm{mPFC}$ and $\mathrm{vHC}$ inputs onto $\mathrm{mPFC}$-projecting BA neurons in a subset of animals that were co-injected with retrobeads in the
mPFC (Figures 1, 2). We first compared mPFC-backprojecting principal neurons (bPN) with their unlabeled neighboring cells (uPN). Although we cannot rule out false-negatives among uPNs, we assume that the vast majority of these cells do not project to mPFC. Overall, both mPFC and vHC inputs to bPN and uPN displayed identical response type distributions that included excitation and feedforward inhibition (Figures 8A,B). Additionally, these distributions resembled those observed for the entire PN population for both mPFC and vHC inputs (c.f. Figure 3D, all Fisher's Exact Tests: $p>0.15$ ).

When assessing properties of mPFC- and vHC-evoked EPSCs, we detected no difference between uPNs and bPNs within each input type (Table 2, all $t$-tests: $p>0.06$ ). However, when comparing $\mathrm{mPFC}$ and $\mathrm{vHC}$ inputs to either bPNs or uPNs, we found the same significant changes in EPSC kinetics (except decay time), and in paired-pulse properties (Table 2). This confirms and supports our previous findings, and suggests that EPSC properties in 


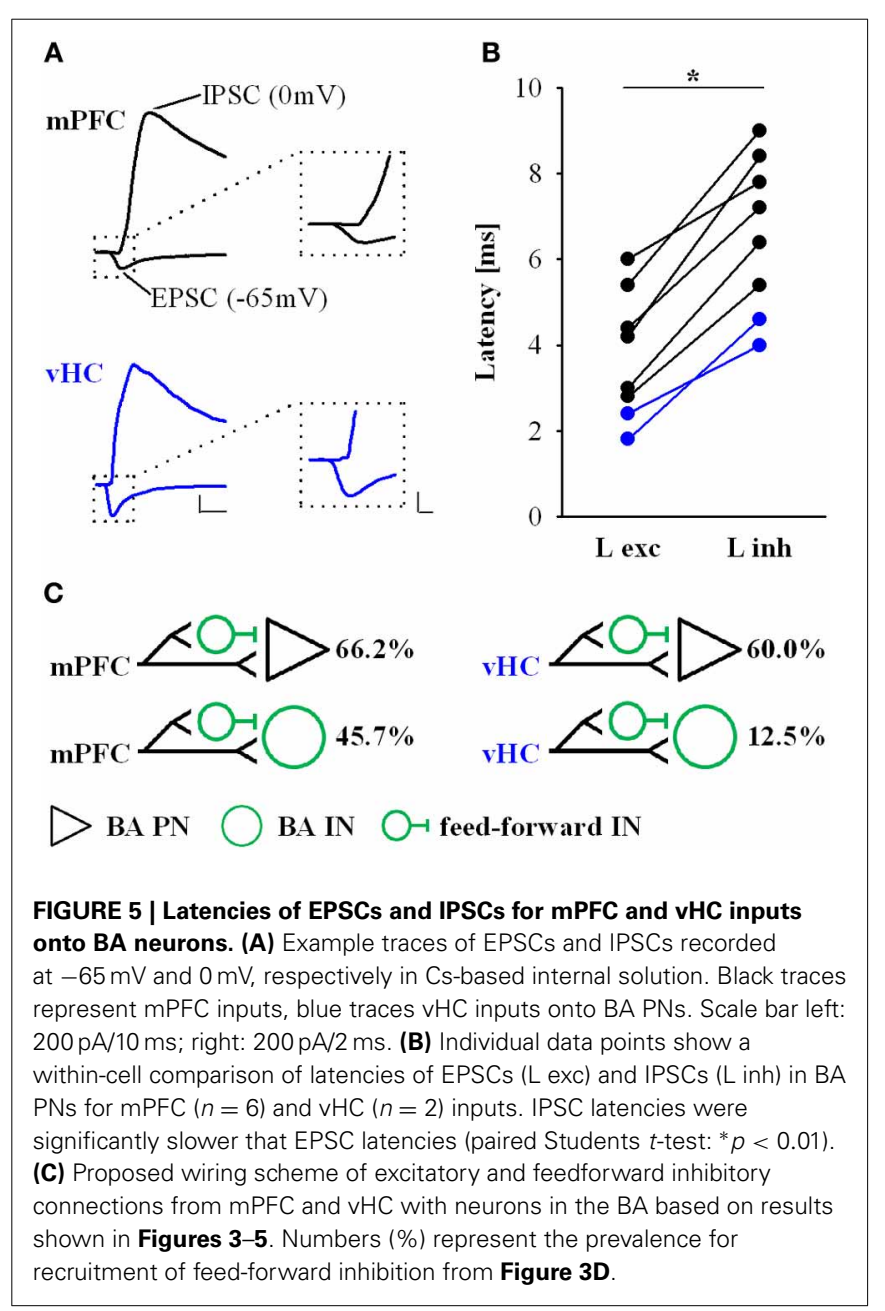

BA PNs are determined by afferent specificity rather than projection target specificity. Interestingly, when analyzing the I/E ratio, we revealed that cells that do not project to the mPFC (uPNs) received significantly less inhibition upon $\mathrm{mPFC}$ compared to vHC input stimulation (Figure 8C).

We next dissected inputs and outputs of BA PNs for subregions of the $\mathrm{mPFC}$. In our dataset, we found the following combinations of inputs and outputs: $\mathrm{mPFC} \rightarrow \mathrm{PL}$-projecting $\mathrm{PN}($ plPN $)(n=3), \mathrm{mPFC} \rightarrow \mathrm{IL}-$ projecting $\mathrm{PN}(\mathrm{ilPN})(n=1)$, $\mathrm{IL} \rightarrow \operatorname{plPN}(n=2)$ and $\mathrm{PL} \rightarrow \operatorname{plPN}(n=17), \mathrm{vHC} \rightarrow \operatorname{plPN}(n=$ $11)$, and $\mathrm{vHC} \rightarrow$ ilPN $(n=10)$. When comparing input properties in the three most frequently observed groups $(\mathrm{PL} \rightarrow \mathrm{plPN}$, $\mathrm{vHC} \rightarrow$ plPN, and $\mathrm{vHC} \rightarrow \mathrm{ilPN}$, Table 3 ), we again revealed feedforward inhibition as a salient feature, which was particularly prevalent at $\mathrm{vHC}$ inputs to PL-projecting cells, but not significantly different from the overall population of PNs (c.f Figures 3D, 8D,E; Fisher's Exact Test, $p=0.14$ ). Similar to the results above, properties of EPSCs appeared to be determined by input rather than output type for PNs (Table 3). Interestingly, the I/E ratio in neurons with feedforward inhibition was similar for vHC inputs onto PL- and IL- projecting cells, and similar for vHC and PL inputs onto PL-projecting cells (Figure 8F).

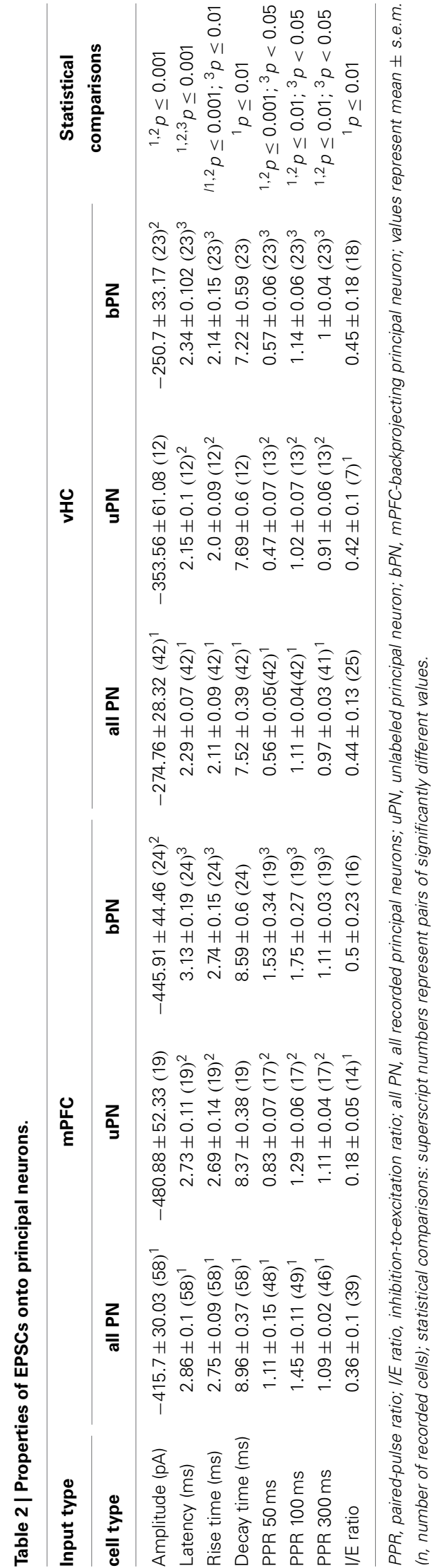




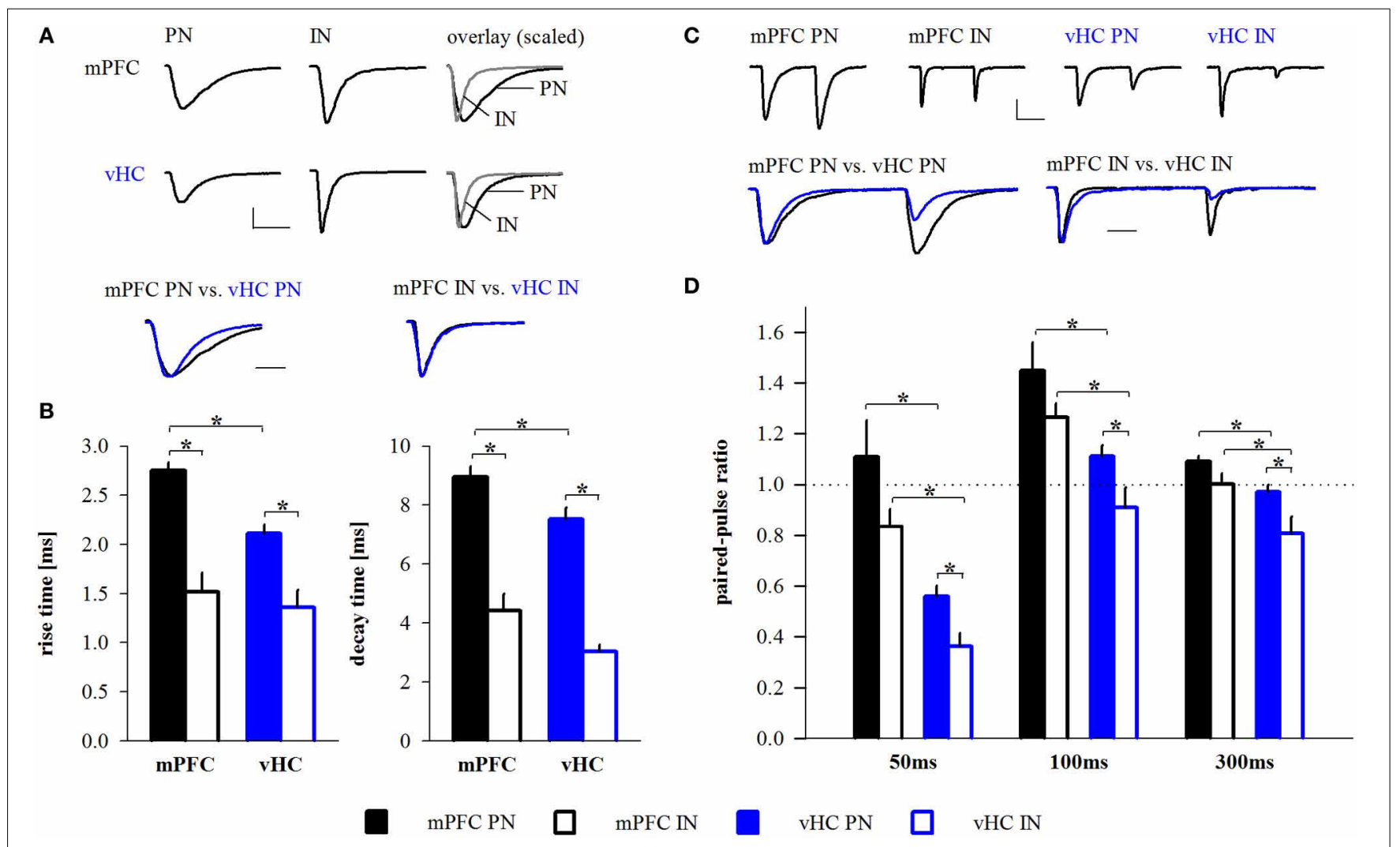

FIGURE 6 | Properties of mPFC- and vHC-evoked EPSCs in BA neurons. (A) Example traces of EPSCs recorded at $-70 \mathrm{mV}$ in BA principal neurons (PN) and interneurons (IN) receiving input from mPFC (top) or vHC (middle) and amplitude-scaled overlays showing faster rise and decay of EPSCs in IN. Amplitude-scaled overlays of mPFC- or vHC-evoked EPSCs in PNs and INs show faster EPSCs of $v H C$ inputs in PNs (bottom). Scale bars: $100 \mathrm{pA} / 10 \mathrm{~ms}$ (top) and $5 \mathrm{~ms}$ (bottom). (B) Summary graphs for rise and decay times of EPSCs in PNs and INs for mPFC (black) and vHC inputs (blue), all values are in Table 2 (all PNs) and Table 5 (all INs). Rise and decay times were significantly faster for mPFC inputs onto INs vs. PNs (rise time: $p<0.001$; decay time: $p<0.001$ ) and $\mathrm{vHC}$ inputs onto INs vs. PNs (rise time: $p=0.002$; decay time: $p<0.001)$. vHC inputs evoked faster EPSCs in PNs than mPFC inputs

In summary, our data suggest reciprocal connections from $\mathrm{mPFC}$ to $\mathrm{mPFC}$-projecting cells in the BA, and a pathway from $\mathrm{vHC}$ to $\mathrm{mPFC}$ via $\mathrm{BA}$ projection neurons that target both, $\mathrm{PL}$ and IL. Synaptic properties in these pathways and connections are regulated by input rather than output specificity.

\section{mPFC AND vHC INPUTS TARGET DIVERSE CLASSES OF INTERNEURONS IN THE BA}

The basolateral amygdala harbors different types of local interneurons with partially distinct physiological and molecular signatures (Ehrlich et al., 2009; Spampanato et al., 2011). To address the diversity of interneurons receiving input from $\mathrm{mPFC}$ and $\mathrm{vHC}$, we analyzed some of their passive and active properties, but found no overall differences (Table 4). However, in spike input-output curves, we observed a tendency of INs with vHC input to fire action potentials with higher frequencies (not shown). One group of INs that can be unequivocally identified electrophysiologically, are fast-spiking interneurons. Therefore, (rise time: $p<0.001$, decay time: $p=0.01$ ). (C) Example traces of EPSCs evoked by paired pulse stimulation (interval: $50 \mathrm{~ms}$ ) at $-70 \mathrm{mV}$ in PNs and INs after stimulation of mPFC (top left) or vHC (top right) inputs. Overlays scaled to the amplitude of the first EPSC illustrate differences in paired pulse ratio (bottom). Scale bars: $100 \mathrm{pA} / 25 \mathrm{~ms}$ (top) and $10 \mathrm{~ms}$ (bottom). (D) Summary graph for paired pulse ratios (PPR) of EPSCs at different stimulation intervals in PNs and INs for mPFC (black) and VHC inputs (blue), all values are in

Table 2 (all PNs) and Table 5 (all INs). PPRs of mPFC inputs onto INs vs. PNs were not significantly different ( $p>0.05$ for all intervals). PPRs of $\mathrm{vHC}$ inputs onto PNs vs. INs were significantly larger $(* p<0.05$ for all intervals). PNs and INs receiving $m P F C$ input showed significantly larger PPRs than PNs and INs receiving $\mathrm{VHC}$ inputs (PN: ${ }^{*} p<0.01 ; \mathrm{IN}:{ }^{*} p<0.05$ for all intervals). we classified individual INs as fast-spiking (fsIN) or non-fast spiking (nfsINs) based on previously published criteria including firing rate and patterns, and spike waveform (Rainnie et al., 2006; Woodruff and Sah, 2007b; Spampanato et al., 2011). Indeed, in both datasets (mPFC or vHC input) cells classified as fsINs exhibited significantly higher spike frequencies in input-output curves than nfsINs, and little spike frequency adaptation (Figures 9A,B). Furthermore, fsINs displayed a significantly shorter spike halfwidth and a more pronounced fast afterhyperpolarization (fAHP) (Figures 9C,D). Some of the fsINs were post-hoc identified as positive for the calcium binding protein parvalbumin (Figure 9F). Within the population of INs with input from mPFC, only $17 \%$ were fsINs, whereas among those with vHC input, $44 \%$ were fsINs (Figure 9E). When comparing this with the expected prevalence of fsINs of $\sim 20 \%$ amongst all INs (McDonald and Mascagni, 2001, 2002; Woodruff and Sah, 2007b), fsIN were overrepresented in the population with vHC, but not with mPFC input $\left(\chi^{2}\right.$-tests, $p=0.02$ and $p=0.65$, respectively). Furthermore, fsINs were 


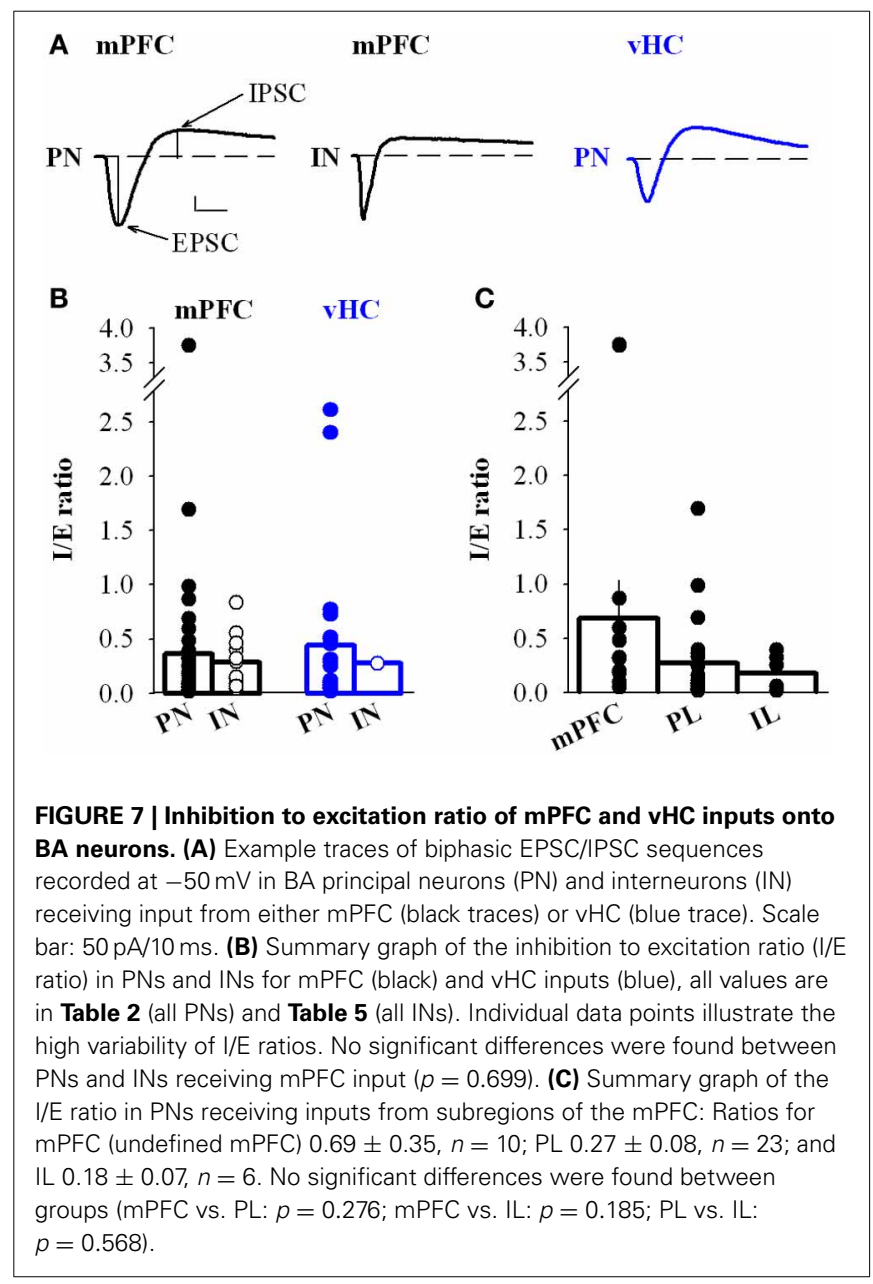

more frequently targeted by vHC than mPFC afferents (Fisher's Exact Test, $p<0.05$ ). When assessing inputs from specific $\mathrm{mPFC}$ injection regions, we observed the following prevalences in connectivity: $\mathrm{mPFC} \rightarrow \mathrm{fsIN}(n=2 / 15,13 \%), \mathrm{PL} \rightarrow \mathrm{fsIN}(n=4 / 16$, $25 \%), \mathrm{IL} \rightarrow \mathrm{fsIN}(n=0 / 4,0 \%)$, suggesting differences between $\mathrm{PL}$ and IL in innervation of INs.

We also tested directly if $\mathrm{mPFC}$ and vHC inputs activate parvalbumin (PV)-expressing INs (pvINs) by recording from cells in PV-reporter mice. In a small sample, we found that mPFC afferent stimulation evoked light responses in pvINs that resembled fsINs $(n=5)$ and vHC afferent stimulation evoked light response in pvINs with more diverse firing patterns and lower average spike frequency ( $n=4$, Figure 9G). However, all targeted pvINs displayed a short spike half-width and large fAHP (Figure 9H). Light responses in pvINs had latencies of $2.5 \pm 0.26 \mathrm{~ms}$ and $2.15 \pm 0.22 \mathrm{~ms}$ (for $\mathrm{mPFC}$ and $\mathrm{vHC}$ input, respectively) consistent with monosynaptic activation.

We next compared response type profiles for different IN types. In agreement with findings for the overall population of INs (Figure 3D), a fraction of nfsINs, fsINs, and pvINs showed feedforward inhibition upon mPFC input activation (Figures 9H,I). In contrast, vHC afferent stimulation elicited feedforward inhibition only in $\leq 25 \%$ of nfsINs and pvINs $(1 / 4$ cells, not firing at high frequency), but in none of the fsINs
(Figures 9I,J). In summary, mPFC and vHC inputs activate nfsINs and fsINs including PV-positive cells. Inputs from mPFC target diverse populations of INs and consistently evoke feedforward inhibition in all IN types. In contrast, vHC inputs are more likely to target fsINs, which in turn do not receive feedforward inhibitory inputs.

\section{DISCUSSION}

We investigated cellular and synaptic interactions between mPFC and $\mathrm{vHC}$ with target neurons in the medial BA, a region innervated by both areas. As expected, PNs and local INs received monosynaptic, excitatory inputs from $\mathrm{mPFC}$ and vHC. In addition, both inputs recruited GABAergic feedforward inhibition in a substantial fraction of PNs, but mPFC inputs more frequently recruited feedforward inhibition onto INs, suggesting activation of dis-inhibitory circuits in the BA. Amongst the innervated PNs we identify neurons that project back to subregions of the mPFC, indicating a loop between neurons in $\mathrm{MPFC}$ and $\mathrm{BA}$, and a pathway from vHC to $\mathrm{mPFC}$ via BA. A general feature of both mPFCand vHC-evoked EPSCs onto local INs is that they show faster rise and decay kinetics compared to PNs. However, mPFC and vHC inputs to both PNs and INs differ in their presynaptic properties. Our data describe wiring principles and features of synaptic connections from mPFC and vHC to amygdala that may help to interpret functional interactions of these brain areas at the network level.

\section{FEEDFORWARD INHIBITION ONTO BA PROJECTION NEURONS IS A SALIENT FEATURE}

We identified feedforward inhibition onto PNs in the BA as a prominent feature of $\mathrm{mPFC}$ and $\mathrm{vHC}$ inputs. Previous in vivo studies have yielded conflicting results about recruitment of local inhibition in the BLA by mPFC stimulation, possibly due to methodological constraints (Rosenkranz and Grace, 2001, 2002; Likhtik et al., 2005). Our approach is not compromised by activation of en-passant fibers or backfiring of BA projection neurons, and also allowed for detection of small inhibitory currents. We were able to recruit inhibition even at stimulation intensities that did not fire BA PNs. Together with latency and pharmacological analyses, this provides strong evidence for feedforward, rather than exclusive feedback inhibition. Thus, vHC and mPFC inputs to BA are similarly controlled by local feedforward inhibition. As at sensory inputs to the LA, this may serve to limit excitation, and to gate activity and plasticity (Li et al., 1996; Lang and Paré, 1997; Szinyei et al., 2000; Bissière et al., 2003; Shin et al., 2006).

In naïve animals, we found a highly variable inhibition/excitation ratio, even when comparing subgroups of PNs with specific inputs or outputs. This could reflect variability in inhibitory synapse location (perisomatic or proximal vs. distal dendritic), synaptic strength, number of inhibitory synapses on the target cell, or local interaction of inputs. However, we cannot rule out that this may also be partially influenced by technical variations (e.g., number of infected axons, differences in viability of INs, or IN-connectivity in slices). It is conceivable that mPFCand vHC- driven feedforward inhibition is a substrate for plastic changes in BA inhibitory synaptic markers (Chhatwal et al., 2005; Heldt and Ressler, 2007), or in inhibitory innervation of 


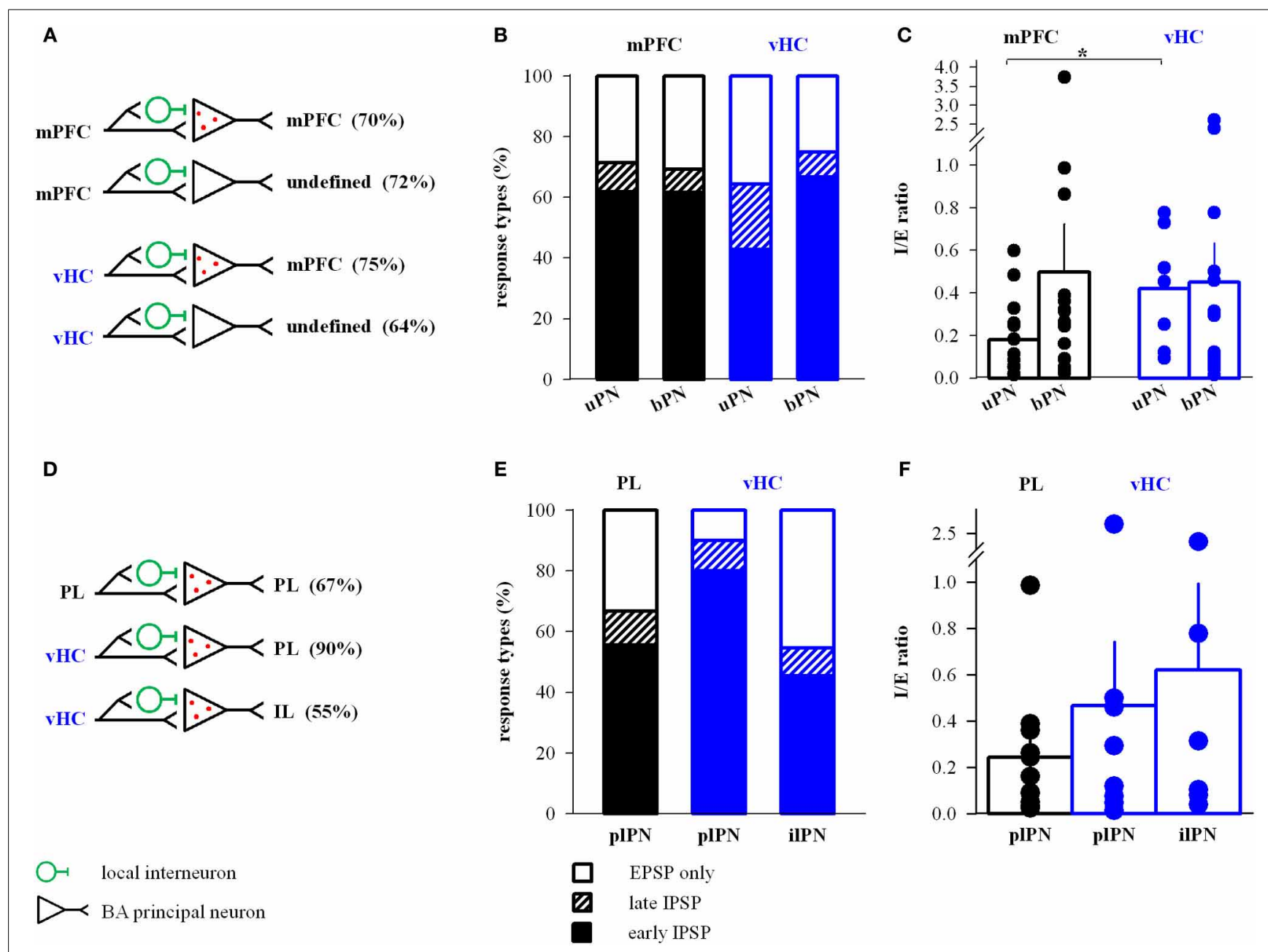

FIGURE 8 | mPFC and vHC connectivity with and properties of inputs to BA projection neurons. (A) Scheme of projections observed onto retrobead-labeled mPFC-projecting (bPN) and unlabeled BA principal neurons (UPN). (B) Relative distribution (\%) of purely excitatory (open bars) and additional inhibitory response types (early IPSP: closed bars, late IPSP: striped bars) in UPNs and bPNs. Occurrence of inhibitory response types for $\mathrm{mPFC} \rightarrow \mathrm{UPN}$ : early $62 \%$, late $10 \%, n=21 ; \mathrm{mPFC} \rightarrow \mathrm{bPN}$ : early $62 \%$, late $8 \%, n=26 ; \mathrm{vHC} \rightarrow \mathrm{uPN}$ : early $43 \%$, late $21 \%, n=14$; and $\mathrm{vHC} \rightarrow \mathrm{bPN}$ : early $67 \%$, late $8 \%, n=24$. No significant differences were found between inputs or cell types (Fisher's Exact Test, $p>0.05$ ). (C) Summary graph of inhibition-to-excitation ratio (I/E ratio) in uPNs and bPNs for mPFC (black) and vHC inputs (blue). All values are in Table 2 Individual data points illustrate the high variability of I/E ratios. Synaptic inputs onto UPNs showed significantly lower I/E ratios for MPFC inputs vs. vHC inputs (uPN mPFC vs. vHC: $p=0.027$; all other comparisons: ${ }^{*} p>0.05$ ). (D) Scheme of specific projections observed onto retrobead labeled PNs projecting to PL (pIPN) and IL (ilPN) subdivisions of the mPFC. (E) Relative distribution (\%) of purely excitatory (open bars) and additional inhibitory response types (early IPSP: closed bars, late IPSP: striped bars) in pIPNs and ilPNs. Occurrence of inhibitory response types for $\mathrm{PL} \rightarrow \mathrm{pIPN}$ : early $56 \%$, late $11 \%, n=12 ; \mathrm{vHC} \rightarrow \mathrm{pIPN}$ : early $80 \%$, late $10 \%, n=10 ; \mathrm{vHC} \rightarrow \mathrm{ilPN}$ : early $45 \%$, late $9 \%, n=11$. No significant differences were found between inputs or cell types (Fisher's Exact Test, $p>0.05$ ). (F) Summary graph of $I / E$ ratio in $p I P N s$ and ilPNs for $P L$ (black) and $\mathrm{vHC}$ inputs (blue). All values are in Table 3. Individual data points illustrate the high variability of $\mathrm{I} / \mathrm{E}$ ratios. No significant difference in $1 / E$ ratios was observed for MPFC or vHC inputs onto pIPNs $(p=0.413)$, or $\mathrm{vHC}$ input onto plPNs vs. ilPNs $(p=0.740)$. functionally identified PNs (Trouche et al., 2013) upon fear and extinction learning.

\section{IDENTITY OF INTERNEURONS RECRUITED BY DIFFERENT INPUTS}

Additional evidence for feedforward inhibition stems from reliable activation of local INs in the BA. In keeping with observations in other systems, EPSCs in INs displayed faster kinetics than EPSCs in PNs. This likely results from expression of glutamate receptors with fast kinetics, and enables rapid and temporally precise signaling in feedforward circuits (Jonas et al., 2004; Polepalli et al., 2010). Our data suggest that several types of interneurons are part of feedforward inhibitory circuits, including fast-spiking PV-positive $(\mathrm{PV}+)$ cells, and non-fast spiking PV+ and PVnegative cells. It has been proposed that fast-spiking PV+ INs are part of feedforward circuits in the BA based on their lower than expected innervation by local glutamatergic afferents (Woodruff and Sah, 2007b). On the other hand, cortical (including mPFC) innervation of PV+ cells in the BA was underrepresented compared to local innervation, suggesting that $\mathrm{PV}+$ cells also participate in feedback inhibition (Smith et al., 2000). Our data may 

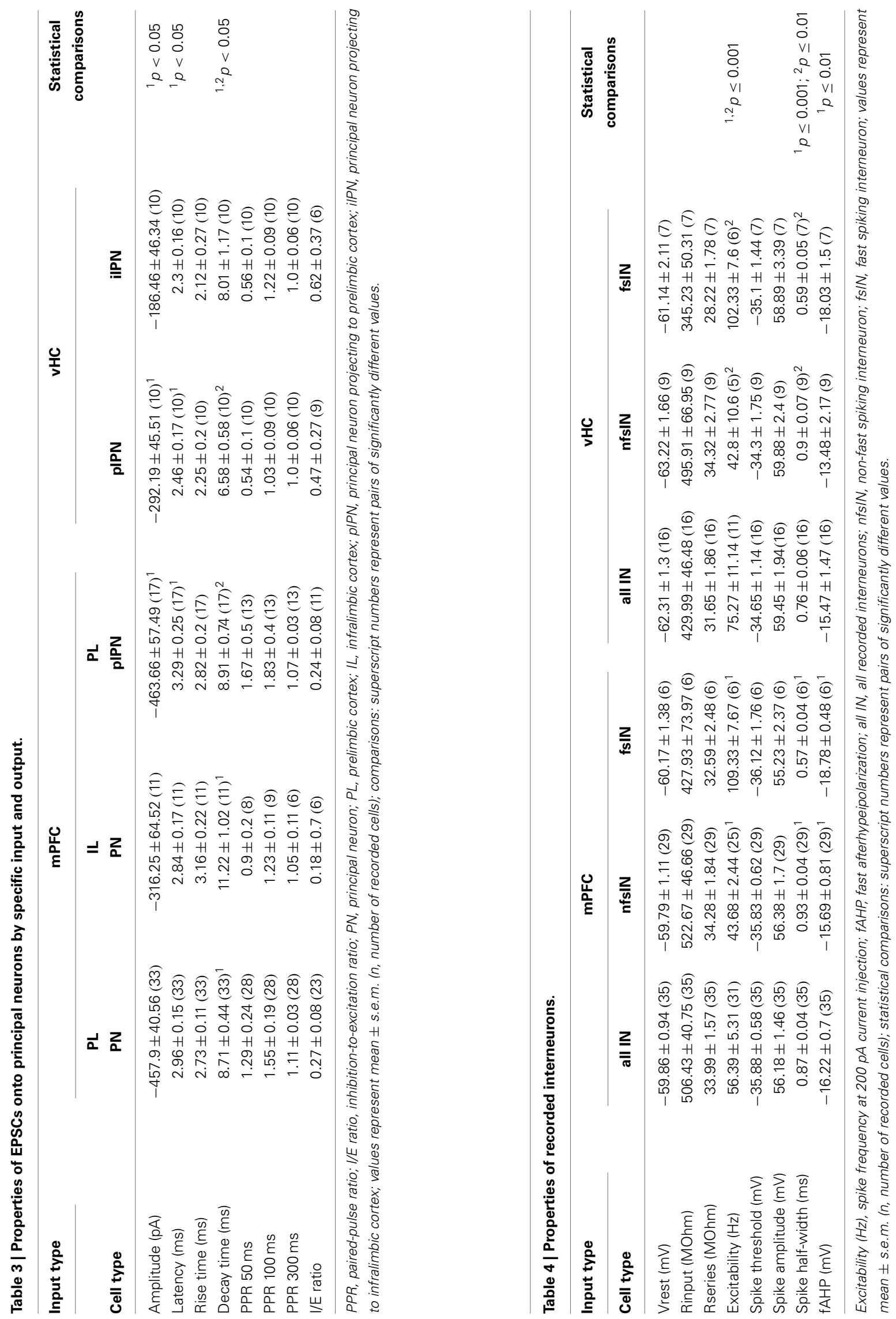


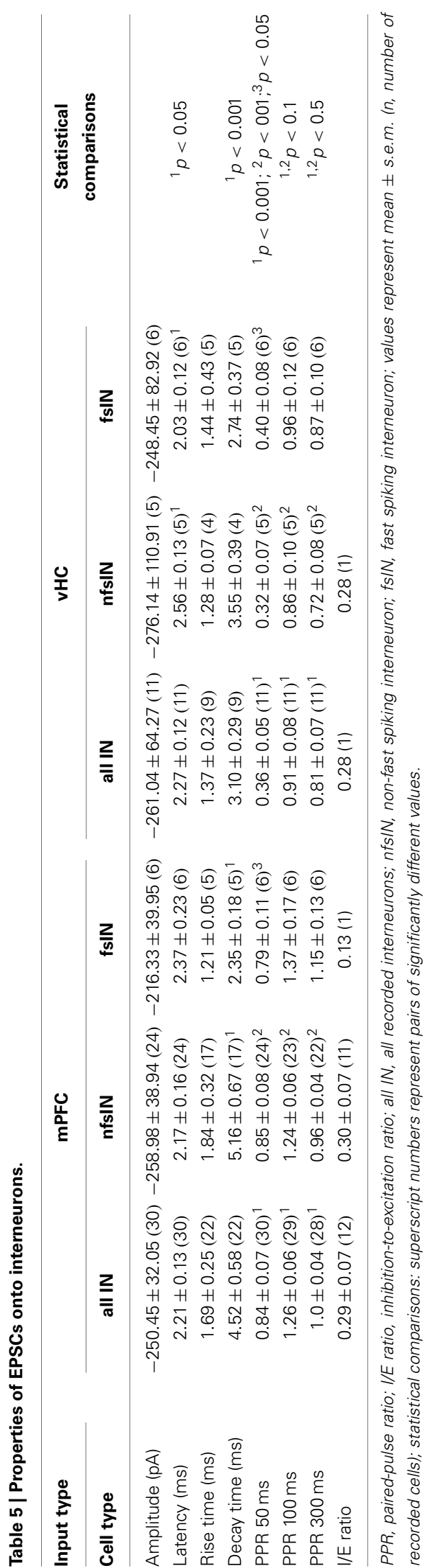

help resolve this discrepancy: We show that fast-spiking PV+ INs receive functional mPFC inputs, but fsINs are not overrepresented amongst targeted INs. In contrast, fast-spiking INs are preferentially activated by vHC afferents, but we also show that regular firing PV+ cells (Rainnie et al., 2006; Woodruff and Sah, 2007b) receive vHC inputs. This suggests that PV+ INs could be important components of $\mathrm{vHC} \rightarrow \mathrm{BA}$ feedforward inhibitory circuits. Overall, whether PV+ cells participate in feedforward or feedback circuits likely depends on the specific inputs that are activated. Since a majority of PV+ cells innervate BA PNs preferentially at the proximal somatodendritic domain (Muller et al., 2006; Rainnie et al., 2006), PV + cell activation may serve to synchronize the output of PNs in the BA in response to intrinsic and extrinsic stimuli (Woodruff and Sah, 2007a).

\section{DIFFERENCES BETWEEN mPFC AND vHC INPUTS}

We discovered three major differences between inputs from mPFC and vHC: Firstly, for INs and PNs, mPFC and vHC inputs showed differences in paired-pulse responses. vHC inputs were depressing, suggesting high release probability. This, together with recruitment of feedforward inhibition could allow for lowpass temporal input filtering. In contrast, mPFC inputs had higher paired-pulse ratios, suggesting a lower release probability. Constant or facilitating excitatory inputs may be able to counterbalance recruited feedforward inhibition and to maintain sustained excitatory responses. Secondly, vHC inputs onto $\mathrm{PNs}$ in the BA showed shorter latencies and faster rise and decay times than mPFC inputs. The most likely explanation is that this arises from differences in dendritic input localization, because EPSC latency, rise, and decay were correlated. We cannot rule out that other parameters such as synchronization of transmitter release, or differences in glutamate receptor properties or synapse anatomy may contribute. Thirdly, we find that mPFC compared to vHC input stimulation more likely results in feedforward inhibition onto targeted INs, suggesting recruitment of dis-inhibitory circuits. We think it is unlikely that this is an artifact of our stimulation conditions, because excitatory and spike responses in INs were similarly present in both pathways, and feedforward inhibition was also similarly recruited in PNs.

\section{IMPLICATIONS FOR NETWORK FUNCTION DURING FEAR-RELATED BEHAVIOR}

It is becoming increasingly clear that the interconnected network of $\mathrm{vHC}, \mathrm{mPFC}$, and BLA subserves multiple roles in expression of fear, emotional memory, and behavioral expression of anxiety. Several distinct features of $\mathrm{vHC}$ inputs onto BA neurons suggest that this input is well suited to entrain synchronous amygdala activity as observed during or after fear conditioning and extinction (Seidenbecher et al., 2003; Lesting et al., 2011). For example, fast and depressing excitatory inputs in concert with feedforward inhibition put a temporal constraint on transmission of incoming activity. Additionally, activation of fast-spiking feedforward inhibitory INs may help to synchronize BA PN activity to other inputs.

The vHC has also been implicated in fear renewal and gating of fear via interactions with the PL and BA. The vHC innervates BA neurons that become active during renewal (Herry et al., 2008), 


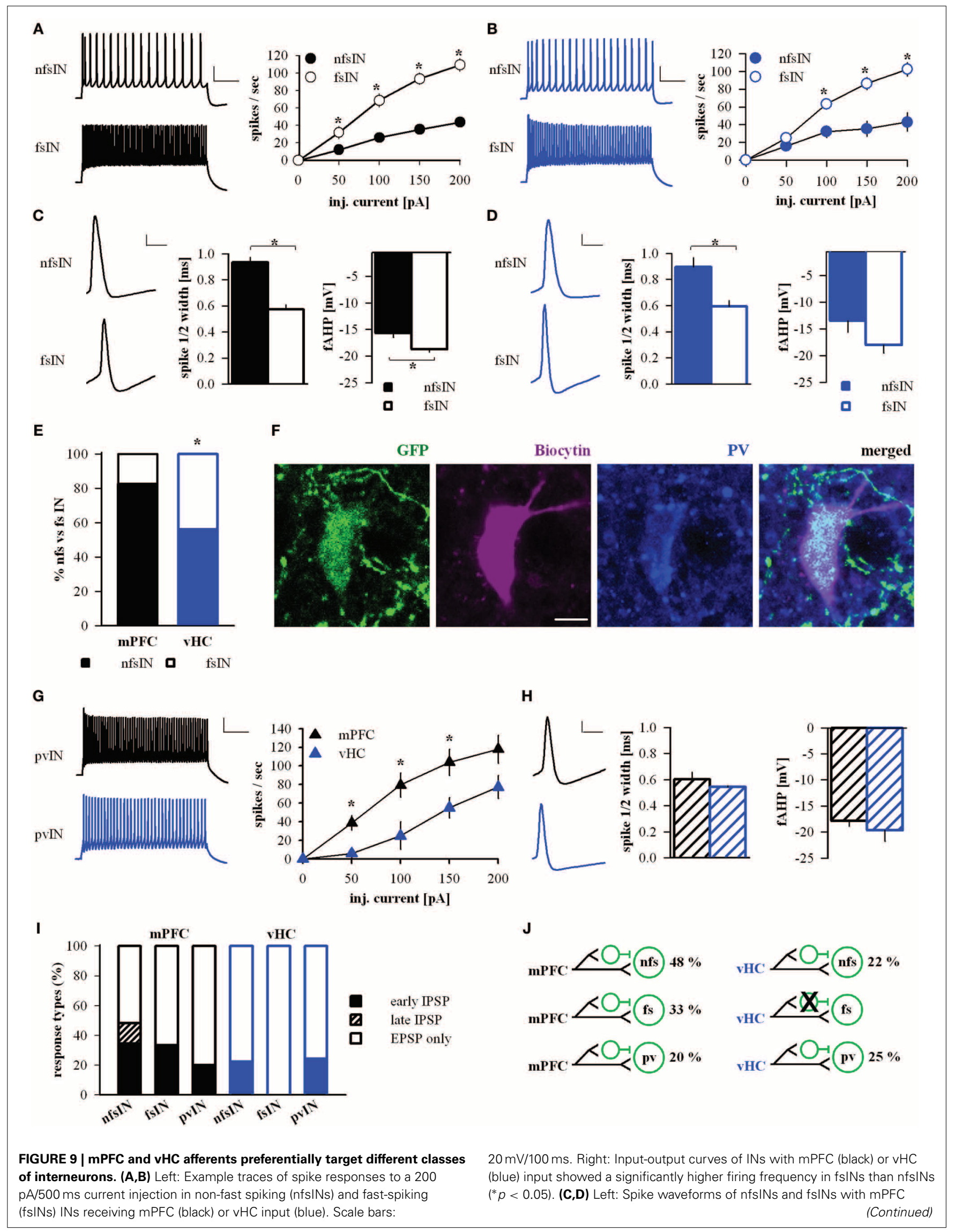




\section{FIGURE 9 | Continued}

(black) or vHC input (blue). Scale bar: $20 \mathrm{mV} / 2 \mathrm{~ms}$. Right: Graphs of spike half-width and fast after hyperpolarisation (fAHP) for nfsINs and fsINs with mPFC (black) or $\mathrm{vHC}$ inputs (blue), all values are in Table 4. Spike half width was broader in nfsINs vs. fsINs (mPFC: $p<0.001 ; v H C$ : $p=0.005)$ and the fAHP was smaller nfsINs vs. fsINs for mPFC inputs (mPFC: $p=0.003 ; v H C: p=0.127$ ). (E) Graph showing the distribution of BA IN-types with light responses (\%). fsIN were more likely to be recruited by $\mathrm{VHC}$ vs. mPFC inputs (Fisher's Exact Test, $p<0.05$ ). (F) Confocal image of fsIN recorded in a GAD67-GFP mouse (green), filled with Biocytin (pink), and identified as PV-positive (blue). Scale bar: $5 \mu \mathrm{m}$. (G) Left: Example traces of spike responses to a $200 \mathrm{pA} / 500 \mathrm{~ms}$ current injection in PV-positive INs from PV-Cre reporter mice (pvIN) receiving mPFC (black) or $\mathrm{vHC}$ inputs (blue). Scale bar: $20 \mathrm{mV} / 100 \mathrm{~ms}$. Right:
Input-output curves show that pvINs receiving mPFC vs. vHC inputs fire with significantly higher frequency $(* p<0.05)$. (H) Left: Spike waveforms in pvINs with mPFC and $\mathrm{VHC}$ input. Scale bar: $20 \mathrm{mV} / 2 \mathrm{~ms}$. Right: Spike half-width and fAHP were similar for pvINs with mPFC or vHC input. Spike half width: $0.6 \pm 0.1 \mathrm{~ms}$ vs. $0.5 \pm 0.0 \mathrm{~ms}$; fAHP $-17.9 \pm 1.1$ vs. $-19.7 \pm 2.1 \mathrm{mV} ; p>0.05$. (I) Relative distribution (\%) of purely excitatory (open bars) and additional inhibitory response types (early IPSP: closed bars, late IPSP: striped bars) in nfsINs, fsINs, and pvINs. Occurrence of inhibitory response types for $\mathrm{mPFC} \rightarrow \mathrm{nfsIN}$ : early $34 \%$, late $14 \%, n=29$; $\mathrm{mPFC} \rightarrow$ fsIN: early $33 \%$, late $0 \%, n=6 ; \mathrm{vHC} \rightarrow \mathrm{nfsIN}$ : early $22 \%$, late $0 \%, n=9$; and $\mathrm{vHC} \rightarrow$ fsIN: early $0 \%$, late $0 \%, n=7$. No significant differences were found between inputs or cell types (Fisher's Exact Test, $p>0.05)$. (J) Wiring scheme of different interneuron types in upon activation of mPFC and $\mathrm{VHC}$ afferents. and BA-projecting neurons in the $\mathrm{vHC}$ and $\mathrm{PL}$ are activated upon renewal (Orsini et al., 2011). This has lead to a model in which convergent inputs from $\mathrm{PL}$ and $\mathrm{vHC}$ drive $\mathrm{BA}$ activity to increase fear output. Although we have no direct evidence, the fact that PL and vHC target PL-projecting BA neurons, supports the idea of input convergence at least onto PL-projecting PNs. Our findings also delineate reciprocal connections between PL and BA PNs. In fact, a modeling study indicates that this bidirectional PL-BA loop can contribute to sustained CS-responses in PL and BA during fear expression and attributes a major role to PL inputs to BLA in this process (Pendyam et al., 2013). This fits well with our observation of non-depressing excitatory PL inputs and activation of dis-inhibitory circuits in the BA, features that could support sustained activation in PL $\rightarrow$ BA circuits. Additionally or in parallel, fear responses can also be regulated at the level of the mPFC. Here, vHC-mediated inhibition is thought to gate BLA-driven PL activation, resulting in turn in a net decrease in BLA activation and reduced fear output (Sotres-Bayon et al., 2012).

At the level of the BLA, it emerges that output specificity of BLA projection neurons also defines their behavioral role. Neurons targeting mPFC subregions or vHC have distinct roles in acquired and extinguished fear states and anxiety. For example, activity of PL- vs. IL-projecting BA cells supports the expression of high fear or low fear after extinction, respectively (Senn et al., 2014). The projection from BA to vHC controls anxiety by mediating excitation and polysynaptic inhibition in the $\mathrm{vHC}$ (Felix-Ortiz et al., 2013). Furthermore, vHC-projecting BA neurons also become activated during expression of acquired fear (Senn et al., 2014). Because vHC-projecting neurons are located in the magnocellular $\mathrm{BA}$, the site of convergence of $\mathrm{vHC}$ and mPFC inputs, it is likely that their activity is also controlled by $\mathrm{mPFC}$ and $\mathrm{vHC}$ inputs to generate behavioral outputs.

We hoped to identify differences in vHC and $\mathrm{mPFC}$ inputs onto mPFC-projecting BA neurons (which include fear and extinction neurons) that could help to explain their responses and roles during distinct high and low fear behavioral states (Herry et al., 2008; Senn et al., 2014). However, in naïve animals, wiring of $\mathrm{mPFC}$ and $\mathrm{vHC}$ inputs and response types in PL- and ILprojecting cells and unlabeled counterparts (largely comprised of neurons projecting outside the $\mathrm{mPFC}$ ) were similar. One important consideration is that not all PL- and IL-projecting cells are fear or extinction neurons, respectively, and input specificity could be limited to a subset of these anatomically defined neurons (Senn et al., 2014). Secondly, specific response types may only emerge through synaptic plasticity upon learning (Vouimba and Maroun, 2011; Cho et al., 2013).

Based on the opposing roles of PL and IL in fear expression and extinction one would expect differences in amygdalar activation by these inputs (Milad and Quirk, 2002; Burgos-Robles et al., 2009; Sierra-Mercado et al., 2011). Our data show that PNs in magnocellular BA are similarly activated and receive similar feedforward inhibition. This is consistent with a recent study suggesting no difference in IL and PL inputs onto BA PNs in naïve animals (Cho et al., 2013). While these authors also suggest that PL and IL inputs onto BA PNs might show equal changes upon fear extinction learning, our data imply that the impact could differ because of differential recruitment of INs that participate in feedforward circuits. Moreover, the effect of PL/IL inputs might also depend on the identity of the postsynaptic $\mathrm{PN}$, and thus might have been overlooked by Cho et al. Indeed, in our hands, IL inputs target mainly non-fast spiking INs, which may be dendrite-targeting INs that either control local plasticity, or are subject to differential modulatory control (Klausberger, 2009; Spampanato et al., 2011; Chiu et al., 2013). Thus, different interneuron subtypes may participate in routing information from defined inputs to distinct and functionally diverse postsynaptic cell populations in the basolateral amygdala.

Taken together, while on the one hand our findings identify some clear differences and specializations, our data reveal a number of general and preserved features of inputs from the IL, PL, and the vHC to neurons and microcircuits in the BA. Changes in the activity of specific BA neurons upon fear and extinction learning (Herry et al., 2008; Amano et al., 2011) could then emerge either in a state-dependent manner, controlled by neuromodulators, and/or due to cellular or synaptic plasticity upon learning. This plasticity may alter recruitment of excitation, feedforward inhibition, or dis-inhibition in a cell-type specific manner. The wiring principles and synaptic features of connections from $\mathrm{mPFC}$ and $\mathrm{vHC}$ to $\mathrm{BA}$ described here serve as a foundation for further investigations into the roles of these inputs during fear and anxiety-related behavior, and into elucidating specific sites and mechanisms of plasticity within these circuits in vivo and ex vivo. 


\section{ACKNOWLEDGMENTS}

This work was supported by funding from the Hertie Foundation, the Centre for Integrative Neuroscience (DFG, Exc 307), and a NARSAD Young Investigator Award (to Ingrid Ehrlich). We would like to thank members of the Ehrlich lab for comments throughout the work and Verena Senn for comments on an earlier version of the manuscript. We acknowledge support by the Deutsche Forschungsgemeinschaft and Open Access Publishing Fund of Tuebingen University.

\section{REFERENCES}

Amano, T., Duvarci, S., Popa, D., and Pare, D. (2011). The fear circuit revisited: contributions of the basal amygdala nuclei to conditioned fear. J. Neurosci. 31, 15481-15489. doi: 10.1523/JNEUROSCI.3410-11.2011

Berndt, A., Schoenenberger, P., Mattis, J., Tye, K. M., Deisseroth, K., Hegemann, P., et al. (2011). High-efficiency channelrhodopsins for fast neuronal stimulation at low light levels. Proc. Natl. Acad. Sci. U.S.A. 108, 7595-7600. doi: 10.1073/pnas. 1017210108

Bissière, S., Humeau, Y., and Lüthi, A. (2003). Dopamine gates LTP induction in lateral amygdala by suppressing feedforward inhibition. Nat. Neurosci. 6, 587-592. doi: $10.1038 / \mathrm{nn} 1058$

Bouton, M. E., Westbrook, R. F., Corcoran, K. A., and Maren, S. (2006). Contextual and temporal modulation of extinction: behavioral and biological mechanisms. Biol. Psychiatry 60, 352-360. doi: 10.1016/j.biopsych.2005.12.015

Burgos-Robles, A., Vidal-Gonzalez, I., and Quirk, G. J. (2009). Sustained conditioned responses in prelimbic prefrontal neurons are correlated with fear expression and extinction failure. J. Neurosci. 29, 8474-8482. doi: 10.1523/JNEUROSCI.0378-09.2009

Canteras, N. S., and Swanson, L. W. (1992). Projections of the ventral subiculum to the amygdala, septum, and hypothalamus: a PHAL anterograde tracttracing study in the rat. J. Comp. Neurol. 324, 180-194. doi: 10.1002/cne.9032 40204

Chhatwal, J. P., Davis, M., Maguschak, K. A., and Ressler, K. J. (2005). Enhancing cannabinoid neurotransmission augments the extinction of conditioned fear. Neuropsychopharmacology 30, 516-524. doi: 10.1038/sj.npp.1300655

Chiu, C. Q., Lur, G., Morse, T. M., Carnevale, N. T., Ellis-Davies, G. C., and Higley, M. J. (2013). Compartmentalization of GABAergic inhibition by dendritic spines. Science 340, 759-762. doi: 10.1126/science.1234274

Cho, J. H., Deisseroth, K., and Bolshakov, V. Y. (2013). Synaptic encoding of fear extinction in mPFC-amygdala circuits. Neuron 80, 1491-1507. doi: 10.1016/j.neuron.2013.09.025

Conde, F., Maire-Lepoivre, E., Audinat, E., and Crepel, F. (1995). Afferent connections of the medial frontal cortex of the rat. II. Cortical and subcortical afferents. J. Comp. Neurol. 352, 567-593. doi: 10.1002/cne.903520407

Ehrlich, I., Humeau, Y., Grenier, F., Ciocchi, S., Herry, C., and Lüthi, A. (2009). Amygdala inhibitory circuits and the control of fear memory. Neuron 62, 757-771. doi: 10.1016/j.neuron.2009.05.026

Felix-Ortiz, A. C., Beyeler, A., Seo, C., Leppla, C. A., Wildes, C. P., and Tye, K. M. (2013). BLA to vHPC inputs modulate anxiety-related behaviors. Neuron 79, 658-664. doi: 10.1016/j.neuron.2013.06.016

Heldt, S. A., and Ressler, K. J. (2007). Training-induced changes in the expression of GABAA-associated genes in the amygdala after the acquisition and extinction of Pavlovian fear. Eur. J. Neurosci. 26, 3631-3644. doi: 10.1111/j.14609568.2007.05970.x

Herry, C., Ciocchi, S., Senn, V., Demmou, L., Muller, C., and Lüthi, A. (2008). Switching on and off fear by distinct neuronal circuits. Nature 454, 600-606. doi: 10.1038/nature07166

Herry, C., Ferraguti, F., Singewald, N., Letzkus, J. J., Ehrlich, I., and Lüthi, A. (2010). Neuronal circuits of fear extinction. Eur. J. Neurosci. 31, 599-612. doi: 10.1111/j.1460-9568.2010.07101.x

Hobin, J. A., Goosens, K. A., and Maren, S. (2003). Context-dependent neuronal activity in the lateral amygdala represents fear memories after extinction. J. Neurosci. 23, 8410-8416.

Hoover, W. B., and Vertes, R. P. (2007). Anatomical analysis of afferent projections to the medial prefrontal cortex in the rat. Brain Struct. Funct. 212, 149-179. doi: 10.1007/s00429-007-0150-4
Jonas, P., Bischofberger, J., Fricker, D., and Miles, R. (2004). Interneuron Diversity series: fast in, fast out-temporal and spatial signal processing in hippocampal interneurons. Trends Neurosci. 27, 30-40. doi: 10.1016/j.tins.2003.10.010

Klausberger, T. (2009). GABAergic interneurons targeting dendrites of pyramidal cells in the CA1 area of the hippocampus. Eur. J. Neurosci. 30, 947-957. doi: 10.1111/j.1460-9568.2009.06913.x

Lang, E. J., and Paré, D. (1997). Similar inhibitory processes dominate the responses of cat lateral amygdaloid projection neurons to their various afferents. J. Neurophysiol. 77, 341-352.

Ledoux, J. E. (2000). Emotion circuits in the brain. Annu. Rev. Neurosci. 23, 155-184. doi: 10.1146/annurev.neuro.23.1.155

Lesting, J., Narayanan, R. T., Kluge, C., Sangha, S., Seidenbecher, T., and Pape, H. C. (2011). Patterns of coupled theta activity in amygdala-hippocampalprefrontal cortical circuits during fear extinction. PLOS ONE 6:e21714. doi: 10.1371/journal.pone.0021714

Li, X. F., Armony, J. L., and Ledoux, J. E. (1996). GABAA and GABAB receptors differentially regulate synaptic transmission in the auditory thalamoamygdala pathway: an in vivo microiontophoretic study and a model. Synapse 24, 115-124. doi: 10.1002/(SICI) 1098-2396(199610)24:2\&amp;lt;115::AIDSYN3\&amp;gt;3.0.CO;2-I

Likhtik, E., Pelletier, J. G., Paz, R., and Pare, D. (2005). Prefrontal control of the amygdala. J. Neurosci. 25, 7429-7437. doi: 10.1523/JNEUROSCI.2314-05.2005

Likhtik, E., Stujenske, J. M., Topiwala, M. A., Harris, A. Z., and Gordon, J. A. (2014). Prefrontal entrainment of amygdala activity signals safety in learned fear and innate anxiety. Nat. Neurosci. 17, 106-113. doi: 10.1038/nn.3582

Madisen, L., Zwingman, T. A., Sunkin, S. M., Oh, S. W., Zariwala, H. A., Gu, H., et al. (2010). A robust and high-throughput Cre reporting and characterization system for the whole mouse brain. Nat. Neurosci. 13, 133-140. doi: 10.1038/nn.2467

Mahanty, N. K., and Sah, P. (1998). Calcium-permeable AMPA receptors mediate long-term potentiation in interneurons in the amygdala. Nature 394, 683-687. doi: $10.1038 / 29312$

Maren, S. (2001). Neurobiology of Pavlovian fear conditioning. Annu. Rev. Neurosci. 24, 897-931. doi: 10.1146/annurev.neuro.24.1.897

Maren, S. (2011). Seeking a spotless mind: extinction, deconsolidation, and erasure of fear memory. Neuron 70, 830-845. doi: 10.1016/j.neuron.2011.04.023

Maren, S., and Fanselow, M. S. (1995). Synaptic plasticity in the basolateral amygdala induced by hippocampal formation stimulation in vivo. J. Neurosci. 15, 7548-7564.

Maren, S., and Hobin, J. A. (2007). Hippocampal regulation of context-dependent neuronal activity in the lateral amygdala. Learn. Mem. 14, 318-324. doi: 10.1101/lm.477007

Maren, S., and Quirk, G. J. (2004). Neuronal signalling of fear memory. Nat. Rev. Neurosci. 5, 844-852. doi: 10.1038/nrn1535

McDonald, A. J., and Mascagni, F. (2001). Colocalization of calcium-binding proteins and GABA in neurons of the rat basolateral amygdala. Neuroscience 105, 681-693. doi: 10.1016/S0306-4522(01)00214-7

McDonald, A. J., and Mascagni, F. (2002). Immunohistochemical characterization of somatostatin containing interneurons in the rat basolateral amygdala. Brain Res. 943, 237-244. doi: 10.1016/S0006-8993(02)02650-1

McDonald, A. J., Mascagni, F., and Guo, L. (1996). Projections of the medial and lateral prefrontal cortices to the amygdala: a Phaseolus vulgaris leucoagglutinin study in the rat. Neuroscience 71, 55-75. doi: 10.1016/0306-4522(95)00417-3

Milad, M. R., and Quirk, G. J. (2002). Neurons in medial prefrontal cortex signal memory for fear extinction. Nature 420, 70-74. doi: 10.1038/nature01138

Morozov, A., Sukato, D., and Ito, W. (2011). Selective suppression of plasticity in amygdala inputs from temporal association cortex by the external capsule. J. Neurosci. 31, 339-345. doi: 10.1523/JNEUROSCI.553710.2011

Muller, J. F., Mascagni, F., and McDonald, A. J. (2006). Pyramidal cells of the rat basolateral amygdala: synaptology and innervation by parvalbuminimmunoreactive interneurons. J. Comp. Neurol. 494, 635-650. doi: $10.1002 /$ cne. 20832

Myers, K. M., and Davis, M. (2007). Mechanisms of fear extinction. Mol. Psychiatry 12, 120-150. doi: 10.1038/sj.mp.4001939

Orsini, C. A., Kim, J. H., Knapska, E., and Maren, S. (2011). Hippocampal and prefrontal projections to the basal amygdala mediate contextual regulation of fear after extinction. J. Neurosci. 31, 17269-17277. doi: 10.1523/JNEUROSCI.409511.2011 
Pape, H. C., and Pare, D. (2010). Plastic synaptic networks of the amygdala for the acquisition, expression, and extinction of conditioned fear. Physiol. Rev. 90, 419-463. doi: 10.1152/physrev.00037.2009

Paré, D., Quirk, G. J., and Ledoux, J. E. (2004). New vistas on amygdala networks in conditioned fear. J. Neurophysiol. 92, 1-9. doi: 10.1152/jn.00153.2004

Paxinos, G., and Franklin, K. B. (2001). The Mouse Brain in Stereotaxic Coordinates. Academic Press.

Pendyam, S., Bravo-Rivera, C., Burgos-Robles, A., Sotres-Bayon, F., Quirk, G. J., and Nair, S. S. (2013). Fear signaling in the prelimbic-amygdala circuit: a computational modeling and recording study. J. Neurophysiol. 110, 844-861. doi: 10.1152/jn.00961.2012

Phelps, E. A., and Ledoux, J. E. (2005). Contributions of the amygdala to emotion processing: from animal models to human behavior. Neuron 48, 175-187. doi: 10.1016/j.neuron.2005.09.025

Pinard, C. R., Mascagni, F., and McDonald, A. J. (2012). Medial prefrontal cortical innervation of the intercalated nuclear region of the amygdala. Neuroscience 205, 112-124. doi: 10.1016/j.neuroscience.2011.12.036

Pinto, A., and Sesack, S. R. (2000). Limited collateralization of neurons in the rat prefrontal cortex that project to the nucleus accumbens. Neuroscience 97, 635-642. doi: 10.1016/S0306-4522(00)00042-7

Pinto, A., and Sesack, S. R. (2008). Ultrastructural analysis of prefrontal cortical inputs to the rat amygdala: spatial relationships to presumed dopamine axons and D1 and D2 receptors. Brain Struct. Funct. 213, 159-175. doi: 10.1007/s00429-008-0180-6

Pitkanen, A., Pikkarainen, M., Nurminen, N., and Ylinen, A. (2000). Reciprocal connections between the amygdala and the hippocampal formation, perirhinal cortex, and postrhinal cortex in rat. A review. Ann. N. Y. Acad. Sci. 911, 369-391. doi: 10.1111/j.1749-6632.2000.tb06738.x

Polepalli, J. S., Sullivan, R. K., Yanagawa, Y., and Sah, P. (2010). A specific class of interneuron mediates inhibitory plasticity in the lateral amygdala. J. Neurosci. 30, 14619-14629. doi: 10.1523/JNEUROSCI.3252-10.2010

Quirk, G. J., Likhtik, E., Pelletier, J. G., and Paré, D. (2003). Stimulation of medial prefrontal cortex decreases the responsiveness of central amygdala output neurons. J. Neurosci. 23, 8800-8807.

Quirk, G. J., and Mueller, D. (2008). Neural mechanisms of extinction learning and retrieval. Neuropsychopharmacology 33, 56-72. doi: 10.1038/sj.npp. 1301555

Rainnie, D. G., Mania, I., Mascagni, F., and McDonald, A. J. (2006). Physiological and morphological characterization of parvalbumin-containing interneurons of the rat basolateral amygdala. J. Comp. Neurol. 498, 142-161. doi: 10.1002/cne. 21049

Rosenkranz, J. A., and Grace, A. A. (2001). Dopamine attenuates prefrontal cortical suppression of sensory inputs to the basolateral amygdala of rats. J. Neurosci. 21, 4090-4103.

Rosenkranz, J. A., and Grace, A. A. (2002). Cellular mechanisms of infralimbic and prelimbic prefrontal cortical inhibition and dopaminergic modulation of basolateral amygdala neurons in vivo. J. Neurosci. 22, 324-337.

Seidenbecher, T., Laxmi, T. R., Stork, O., and Pape, H. C. (2003). Amygdalar and hippocampal theta rhythm synchronization during fear memory retrieval. Science 301, 846-850. doi: 10.1126/science. 1085818

Senn, V., Wolff, S. B. E., Herry, C., Grenier, F., Ehrlich, I., Gruendemann, J., et al. (2014). Long-range connectivity defines behavioral specificity of amygdala neurons. Neuron 81, 428-437. doi: 10.1016/j.neuron.2013.11.006

Shin, R. M., Tsvetkov, E., and Bolshakov, V. Y. (2006). Spatiotemporal asymmetry of associative synaptic plasticity in fear conditioning pathways. Neuron 52, 883-896. doi: 10.1016/j.neuron.2006.10.010

Sierra-Mercado, D., Padilla-Coreano, N., and Quirk, G. J. (2011). Dissociable roles of prelimbic and infralimbic cortices, ventral hippocampus, and baso- lateral amygdala in the expression and extinction of conditioned fear. Neuropsychopharmacology 36, 529-538. doi: 10.1038/npp.2010.184

Smith, Y., Paré, J. F., and Paré, D. (2000). Differential innervation of parvalbuminimmunoreactive interneurons of the basolateral amygdaloid complex by cortical and intrinsic inputs. J. Comp. Neurol. 416, 496-508. doi: 10.1002/(SICI)10969861(20000124)416:4\%3C496::AID-CNE6\%3E3.3.CO;2-E

Sotres-Bayon, F., Sierra-Mercado, D., Pardilla-Delgado, E., and Quirk, G. J. (2012). Gating of fear in prelimbic cortex by hippocampal and amygdala inputs. Neuron 76, 804-812. doi: 10.1016/j.neuron.2012.09.028

Spampanato, J., Polepalli, J., and Sah, P. (2011). Interneurons in the basolateral amygdala. Neuropharmacology 60, 765-773. doi: 10.1016/j.neuropharm.2010.11.006

Szinyei, C., Heinbockel, T., Montagne, J., and Pape, H. C. (2000). Putative cortical and thalamic inputs elicit convergent excitation in a population of GABAergic interneurons of the lateral amygdala. J. Neurosci. 20, 8909-8915.

Tamamaki, N., Yanagawa, Y., Tomioka, R., Miyazaki, J., Obata, K., and Kaneko, T. (2003). Green fluorescent protein expression and colocalization with calretinin, parvalbumin, and somatostatin in the GAD67-GFP knock-in mouse. J. Comp. Neurol. 467, 60-79. doi: 10.1002/cne.10905

Trouche, S., Sasaki, J. M., Tu, T., and Reijmers, L. G. (2013). Fear extinction causes target-specific remodeling of perisomatic inhibitory synapses. Neuron 80 , 1054-1065. doi: 10.1016/j.neuron.2013.07.047

Tye, K. M., Prakash, R., Kim, S. Y., Fenno, L. E., Grosenick, L., Zarabi, H., et al. (2011). Amygdala circuitry mediating reversible and bidirectional control of anxiety. Nature 471, 358-362. doi: 10.1038/nature09820

Vertes, R. P. (2004). Differential projections of the infralimbic and prelimbic cortex in the rat. Synapse 51, 32-58. doi: 10.1002/syn.10279

Vidal-Gonzalez, I., Vidal-Gonzalez, B., Rauch, S. L., and Quirk, G. J. (2006). Microstimulation reveals opposing influences of prelimbic and infralimbic cortex on the expression of conditioned fear. Learn. Mem. 13, 728-733. doi: 10.1101/lm.306106

Vouimba, R. M., and Maroun, M. (2011). Learning-induced changes in mPFCBLA connections after fear conditioning, extinction, and reinstatement of fear. Neuropsychopharmacology 36, 2276-2285. doi: 10.1038/npp.2011.115

Woodruff, A. R., and Sah, P. (2007a). Inhibition and synchronization of basal amygdala principal neuron spiking by parvalbumin-positive interneurons. J. Neurophysiol. 98, 2956-2961. doi: 10.1152/jn.00739.2007

Woodruff, A. R., and Sah, P. (2007b). Networks of parvalbumin-positive interneurons in the basolateral amygdala. J. Neurosci. 27, 553-563. doi: 10.1523/JNEUROSCI.3686-06.2007

Conflict of Interest Statement: The authors declare that the research was conducted in the absence of any commercial or financial relationships that could be construed as a potential conflict of interest.

Received: 30 November 2013; paper pending published: 21 January 2014; accepted: 13 February 2014; published online: 05 March 2014.

Citation: Hübner C, Bosch D, Gall A, Lüthi A and Ehrlich I (2014) Ex vivo dissection of optogenetically activated $m P F C$ and hippocampal inputs to neurons in the basolateral amygdala: implications for fear and emotional memory. Front. Behav. Neurosci. 8:64. doi: 10.3389/fnbeh.2014.00064

This article was submitted to the journal Frontiers in Behavioral Neuroscience. Copyright (c) 2014 Hübner, Bosch, Gall, Lüthi and Ehrlich. This is an open-access article distributed under the terms of the Creative Commons Attribution License (CC BY). The use, distribution or reproduction in other forums is permitted, provided the original author(s) or licensor are credited and that the original publication in this journal is cited, in accordance with accepted academic practice. No use, distribution or reproduction is permitted which does not comply with these terms. 